\title{
Response Analysis of Asphalt Pavement under Dynamic Loadings: Loading Equivalence
}

\author{
Lian-sheng Gao, Han-cheng Dan (D), and Liang Li \\ School of Civil Engineering, Central South University, No. 22, Shaoshan South Road, Central South University Railway Campus, \\ Changsha, Hunan Province 410075, China
}

Correspondence should be addressed to Han-cheng Dan; danhancheng@csu.edu.cn

Received 5 April 2019; Revised 2 June 2019; Accepted 11 June 2019; Published 18 July 2019

Academic Editor: Surajit Kumar Paul

Copyright (C) 2019 Lian-sheng Gao et al. This is an open access article distributed under the Creative Commons Attribution License, which permits unrestricted use, distribution, and reproduction in any medium, provided the original work is properly cited.

\begin{abstract}
This paper establishes the equivalent relationships between the half-sinusoidal load, triangular load, vertical stepwise load, and moving traffic load. The governing equation was established for analyzing the dynamic responses of pavement, and half-sinusoidal load, triangular load, and vertical stepwise load functions were transformed into Fourier series expressions. The partial differential governing equations were simplified as ordinary differential equations and the analytical solutions were obtained. Further, the solutions were validated through comparing the theoretical results with numerical simulated results. Calculation results revealed that, for unchanged load periods, increasing the amplitudes of the three loads by 1.06, 1.31, and 1.35 times can better simulate the moving traffic loads. For unchanged load function amplitudes, increasing the function periods by 1.07, 2.23, and 2.1 times (for half-sinusoidal, triangular, and vertical stepwise loads, resp.) can improve the simulation performance. The fatigue life of asphalt pavements under the moving traffic load agrees with that of the three load simulations, indicating that the fatigue life of asphalt pavements is only associated with the load amplitude but not the load patterns.
\end{abstract}

\section{Introduction}

Due to the excellent suitability for vehicles, asphalt pavements have become the preferred pavement structure type in highway construction in many countries. Owing to increasing traffic volume, vehicle loads, and vehicle speed on highways in recent years, the requirements for pavement structure reliability and durability have increased. Nevertheless, the mismatch between the growing highspeed heavy-load highway transportation demands and the insufficient lifespan of pavement restricts highway development $[1,2]$. One important factor is the use of the static pavement design system in China, which can hardly assess the actual stress on the pavements and therefore cannot reasonably explain and control the early-stage damages on the pavements. Hence, research of the dynamic response laws of asphalt pavements is significant to analyze pavement damage mechanisms and enhance pavement life spans.

The current focuses in road research have become studying the kinetic behavior of pavement structures under traffic load, discovering the pavement damage mechanism, and how to switch from a static pavement design to a dynamic one. Over recent years, road researchers have conducted many indoor and outdoor studies on the dynamic response of asphalt pavements and formulated various methodologies to refine the design of asphalt pavements [3]. In the past decade, owing to development of computers with high computing powers, different finite methodologies have become effective tools in simulating pavement kinetics and have gained more importance [4-8]. Although finite methodologies consider precise geometric models, actual material structures, and contact stresses of the tires, their calculations are relatively complicated and mesh generation is often required. The number of mesh generations affects the calculated results and the computing process is often time-consuming [9]. Some researchers carried out tracking surveys on asphalt pavements in use and conducted long-term monitoring of the structural behavior of pavements and thereby established models in which various factors affect pavement properties [10-12]. However, this type of study demands relatively long test periods and is labor- and resource-intensive, but 
the results obtained are only applicable to certain specific pavement environments, materials, and load conditions.

It is well known that many literatures analyzed the traffic load with a fixed location of load application, but a changing load size and half-sinusoidal load functions can better simulate actual traffic loads. Many researchers often replaced the actual traffic load with the impulsive load and input the latter in finite calculation models for the dynamic response of asphalt pavements $[9,13-16]$. However, until now, no researcher has applied the method of analytic solution and analyzed the dynamic response of asphalt pavements under half-sinusoidal, triangular, and vertical stepwise load.

Therefore, by analyzing the research results from previous studies, this paper aims at establishing the governing equations of pavement dynamic responses based on the characteristics of semirigid base asphalt pavements, the elastic layer system theory, and soil constitutive equations. Half-sinusoidal load, triangular load, and vertical stepwise load functions were transformed into Fourier calculation expressions and introduced into the governing equations. The governing equation will be solved analytically and verified by comparing the analytic results with the numerical simulated ones. Based on the methodology, the load equivalence will be established in terms of rutting and fatigue life.

\section{Dynamic Response of Asphalt Pavements under Different Load Conditions}

2.1. Loading Patterns of Dynamic Load. There are mainly three loading patterns currently employed in pavement dynamic response analyses: half-sinusoidal impulsive load [17], triangular impulsive load [18], and vertical stepwise load $[15,19]$. Their loading patterns are shown in Figure 1. By controlling their amplitudes and periods, different actual loading patterns can be simulated.

The expressions for the three different impulsive load functions are as follows.

(1) The sinusoidal impulsive load function can be expressed as

$$
F(t)= \begin{cases}F \sin t & 0 \leq t \leq T_{1} \\ 0 & T_{1} \leq t \leq T\end{cases}
$$

(2) The triangular impulsive load function can be expressed as

$$
F(t)= \begin{cases}\frac{2 F}{T_{2}} t & 0 \leq t \leq \frac{T_{2}}{2} \\ -\frac{2 F}{T_{2}}\left(t-T_{2}\right) & \frac{T_{2}}{2}<t \leq T_{2} \\ 0 & T_{2}<t \leq T\end{cases}
$$

(3) The vertical stepwise load function can be expressed as

$$
F(t)= \begin{cases}F & 0 \leq t \leq T_{3} \\ 0 & T_{3}<t \leq T\end{cases}
$$

2.2. Establishment of Governing Equations. The layout of soil foundation and pavement system in this paper was a two-dimensional and eight-layered model, including upper, middle, and lower pavement surface layers, upper, middle, and lower pavement base layers, and upper and lower foundation layers, as shown in Figure 2. Pavement surface, pavement base, and foundation layers were considered to be dry elastic media. Neglecting the compressibility of solid grains in the asphalt mixture, the foundation was fixed on the rigid roadbed at a certain depth; therefore, the displacement of the foundation at a certain depth could be taken as zero. The horizontal width of the structural layers in all pavement systems was set to be infinite. The dynamic governing equations were formulated based on this model [16].

The subject of this study is asphalt concrete pavement, which in general will be regarded as a continuous medium. Different materials have different properties, for instance, asphalt concrete has a higher porosity and a greater overall material strength than soil. Therefore, corresponding to the actual situation, a rutting model suitable for asphalt concrete pavement is established in this study to analyze the rutting formation. The following assumptions were made in setting up the mathematical model.

(1) The deformation of the asphalt concrete is very small.

(2) The aggregates in asphalt concrete are incompressible.

(3) The displacement and stress between the structural layers are continuous.

No consideration will be made of the gradual compaction process of the pavement and the shrinkage process of the pores. Without taking water into account, the following governing equations are obtained [20]:

$$
\begin{array}{r}
-\frac{\partial \sigma_{x}}{\partial x}-\frac{\partial \tau_{z x}}{\partial z}=\rho_{s} \frac{\partial w_{x}}{\partial t} \\
-\frac{\partial \tau_{x z}}{\partial x}-\frac{\partial \sigma_{z}}{\partial z}=\rho_{s} \frac{\partial w_{z}}{\partial t}
\end{array}
$$

In (4), $\sigma_{\mathrm{x}}$ and $\sigma_{\mathrm{z}}$ are the positive stresses of the solids along the $x$ and $z$ directions, respectively (units: $\mathrm{Pa}$ ), and $\tau_{\mathrm{zx}}$ is the shear stress along the $x-z$ plane (units: $\mathrm{Pa}$ ).

For the two-dimensional planar strain problem, the following expressions are obtained from Hooke's principle of stress and strain with damping property of the material:

$$
\begin{aligned}
& \sigma_{x x}^{\prime}=\sigma_{x x}-\alpha p=-2 G\left(\varepsilon_{x x}+\frac{\nu \varepsilon_{v}}{1-2 v}\right) \\
& \sigma_{z z}^{\prime}=\sigma_{z z}-\alpha p=-2 G\left(\varepsilon_{z z}+\frac{\nu \varepsilon_{v}}{1-2 v}\right) \\
& \tau_{x z}=-2 G \varepsilon_{x z} \\
& \tau_{z x}=-2 G \varepsilon_{z x}
\end{aligned}
$$




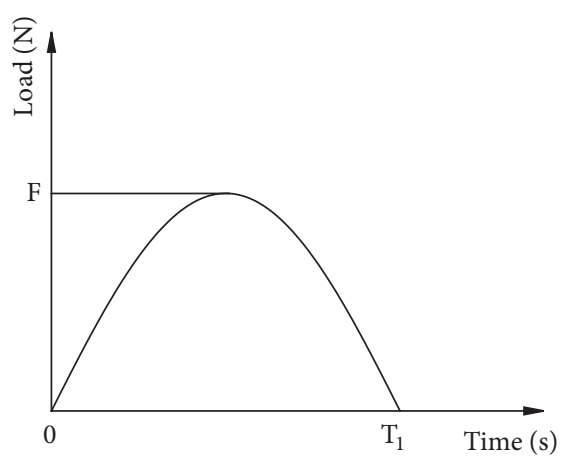

(a) The sinusoidal impulsive load

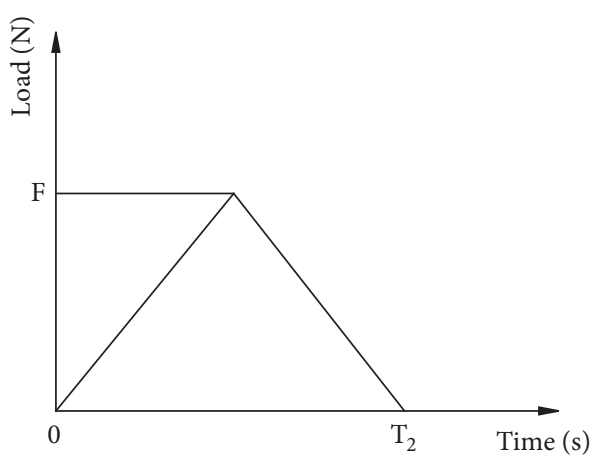

(b) The triangular impulsive load

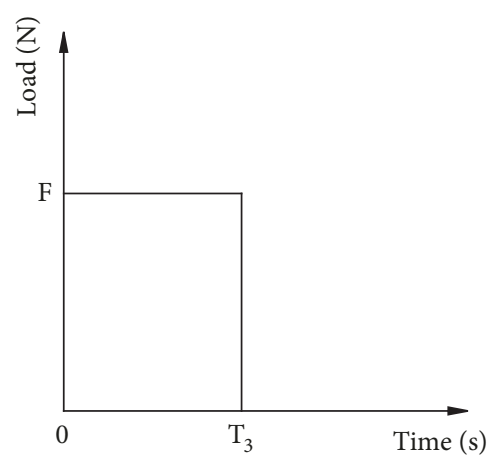

(c) The vertical stepwise load

FIGURE 1: Three typical loading patterns.

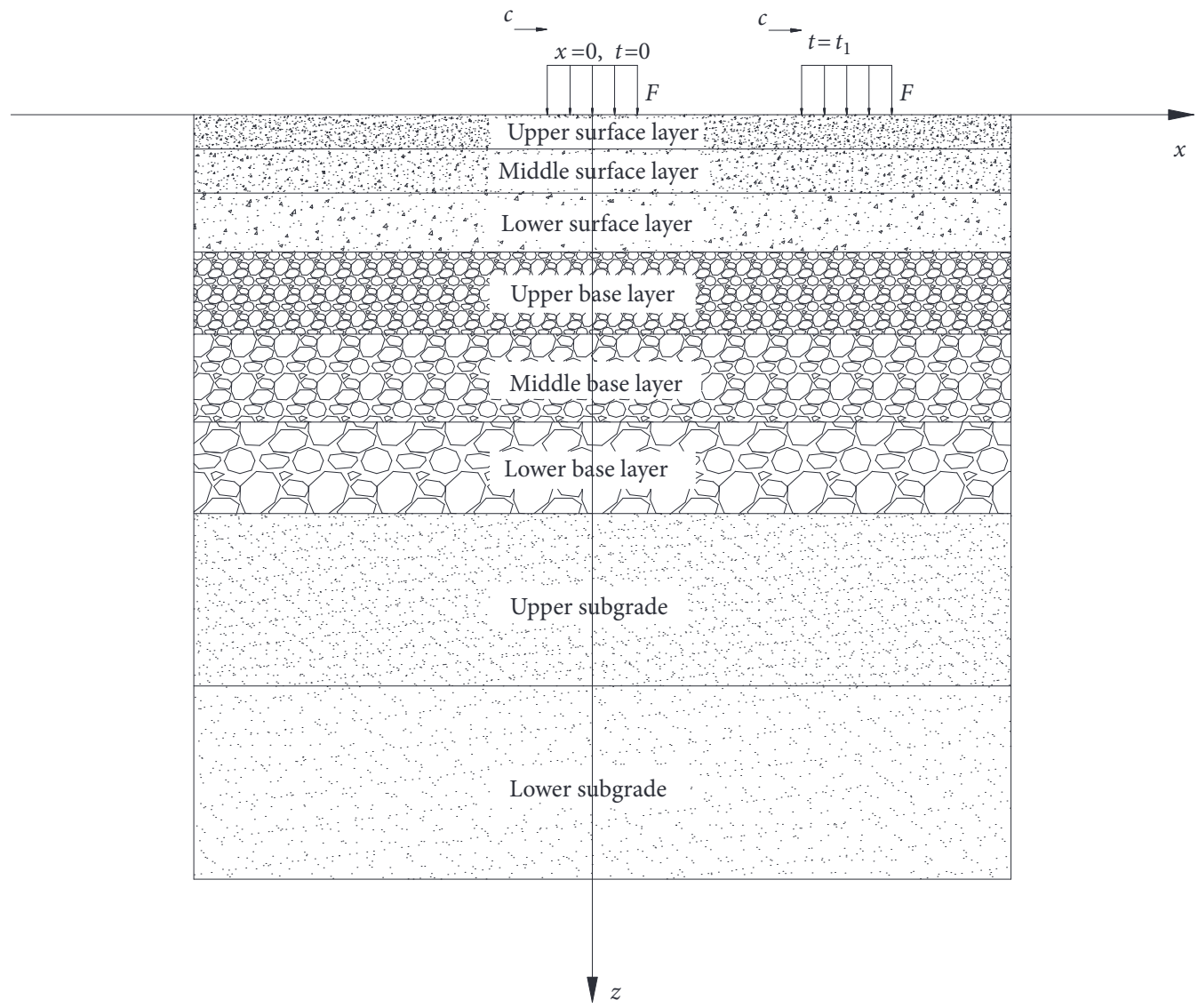

FIGURE 2: Schematic of the roadbed pavement system under loading.

$\varepsilon_{x x}=\frac{\partial \zeta_{x}}{\partial x}$,

$\varepsilon_{z z}=\frac{\partial \zeta_{z}}{\partial z}$

$\varepsilon_{z x}=\varepsilon_{x z}=\frac{1}{2}\left(\frac{\partial \zeta_{x}}{\partial z}+\frac{\partial \zeta_{z}}{\partial x}\right)$

$\varepsilon_{v}=\varepsilon_{x x}+\varepsilon_{z z}$
On the right side of (4), the minus sign designates that the value of a compressive stress is positive. $\sigma_{x x}^{\prime}$ and $\sigma_{z z}^{\prime}$ (units: $\mathrm{Pa})$ are the effective stresses along the horizontal $(x)$ and vertical ( $z$ ) directions, respectively; $\varepsilon_{x x}$ and $\varepsilon_{z z}$ (units: -) are the strains along the $x$ and $z$ directions, respectively; $\zeta_{x}$ and $\zeta_{z}$ (units: -) are the displacements along the $x$ and $z$ directions, respectively; $v$ is the Poisson ratio; and $G^{*}$ (units: $\mathrm{Pa}$ ) is the dynamic shear modulus of the solid material [21].

$$
G^{*}=G(1+2 \delta i), \quad i=\sqrt{-1}
$$


where $\delta$ (units: -) is the damping coefficient of the material and $G$ (units: $\mathrm{Pa}$ ) is the static shear modulus of the solid material.

For the pavement layers, the base layers, and the subgrade, the dynamic governing equations are shown in (10), where $i$ is a layer indicator from 1 to 8 , designating the upper surface layer, the middle surface layer, the lower surface layer, the upper base layer, the middle base layer, the lower base layer, the upper subgrade, and the lower subgrade, respectively:

$$
\begin{aligned}
& \frac{2 G_{i}^{*}\left(1-v_{i}\right)}{1-2 \nu_{i}} \frac{\partial^{2} \zeta_{x i}}{\partial x^{2}}+\left(\frac{2 G_{i}^{*} \nu_{i}}{1-2 \nu_{i}}+G_{i}^{*}\right) \frac{\partial^{2} \zeta_{z i}}{\partial x \partial z} \\
& \quad+G_{i}^{*} \frac{\partial^{2} \zeta_{x i}}{\partial z^{2}}=\rho \frac{\partial^{2} \zeta_{x i}}{\partial t^{2}} \\
& \frac{2 G_{i}^{*}\left(1-v_{i}\right)}{1-2 v_{i}} \frac{\partial^{2} \zeta_{z i}}{\partial z^{2}}+\left(\frac{2 G_{i}^{*} \nu_{i}}{1-2 v_{i}}+G_{i}^{*}\right) \frac{\partial^{2} \zeta_{x i}}{\partial x \partial z} \\
& \quad+G_{i}^{*} \frac{\partial^{2} \zeta_{z i}}{\partial x^{2}}=\rho \frac{\partial^{2} \zeta_{z i}}{\partial t^{2}}
\end{aligned}
$$

In reality, when a vehicle passes through the pavement surface, the load changes in magnitude and location. The dynamic load acting on the pavement structure has two components: (1) changes in the location where the force is applied and (2) changes in the magnitude of the force. The dynamic load acting on the pavement structure is often classified into the following three classes: the moving load, the impact load, and the random load [20]. The random load is the closest to the true load situation on the pavement, but it is relatively difficult to simulate. Both the impact load and moving load can reflect the mobility nature of load movement. The magnitude of the moving load is constant while that of the impact load changes with time. When the pavement surface is relatively smooth and the vehicles vibrate relatively mildly, the effect of the vehicles on the pavement surface can be described by the moving load. Many literatures consider the traffic load as a load with fixed application location but a changing magnitude, and its variation pattern is often represented by half-sinusoidal load function [17, 22, 23].

\subsection{Fourier Transformations for Different Loading Patterns.} In two-dimensional situations, the load applied can be expanded with the Fourier series. After the load passes through a certain point, the dynamic response at that location will gradually diminish until next load application. Assuming the time for the load to be applied once as $t_{0}\left(t_{0}=2 l / c\right)$ (units: $s)$, the time interval between the first load application and the next one is $t_{1}\left(t_{1}=2 L / c\right)$ [24], with load amplitude $F$ (units: $\mathrm{N}$ ), load width $2 l$ (units: $\mathrm{m}$ ), moving speed $c$ (units: $\mathrm{m} / \mathrm{s}$ ), and distance between two loads $2 L$.

The three different load functions can be expressed with the Fourier series as follows.

(1) The sinusoidal impulsive load function can be expressed with the Fourier series as follows:

$$
F(t)=\operatorname{Re} \sum_{m=-\infty}^{\infty} \bar{F}_{m} \exp \left(i \omega_{m} t\right)
$$

In the equation $\omega_{\mathrm{m}}=2 \pi \mathrm{m} / \mathrm{T}, \mathrm{T}$ is the distribution period of the sinusoidal load, which was set to be $2 L / c$ in this paper, $m$ is a constant, and $c$ is the loaded driving speed under the actual situation, ranged from $-\infty$ to $+\infty$ (this is applied to (13) and (15)).

According to the Fourier transformation, $\bar{F}_{m}$ can be represented as

$$
\bar{F}_{m}= \begin{cases}\frac{l}{L} F & m=0 \\ \frac{-2 i m l^{2} F}{c \pi\left(L^{2}-l^{2} m^{2}\right)} \cos \left(\pi m \frac{l}{L}\right) & m \neq 0\end{cases}
$$

(2) The triangular impulsive load function can be expressed with the Fourier series as follows:

$$
F(t)=\operatorname{Re} \sum_{m=-\infty}^{\infty} \overline{\bar{F}}_{m} \exp \left(i \omega_{m} t\right)
$$

According to the Fourier transformation, $\overline{\bar{F}}_{m}$ can be represented as

$$
\overline{\bar{F}}_{m}= \begin{cases}\frac{l}{2 v} F & m=0 \\ \frac{4 L^{2} F}{\pi^{3} m^{2} l v} \sin ^{2}\left(\frac{\pi m l}{4 L}\right) & m \neq 0\end{cases}
$$

(3) The vertical stepwise load function can be expressed with the Fourier series as follows $[16,25,26]$ :

$$
F(t)=\operatorname{Re} \sum_{m=-\infty}^{\infty} \overline{\bar{F}}_{m} \exp \left(i \omega_{m} t\right)
$$

According to the Fourier transformation, $\overline{\bar{F}}_{m}$ can be represented as

$$
\overline{\bar{F}}_{m}= \begin{cases}\frac{l}{L} F & m=0 \\ \frac{F}{\pi m} \sin \left(\pi m \frac{l}{L}\right) & m \neq 0\end{cases}
$$

\subsection{General Solutions for Governing Equations}

2.4.1. Linearization of Governing Equations. For a linear system, an arbitrary function $\varphi(x, z, t)$ can be expressed as the sum of a series of linear harmonic functions [24], which can be written as

$$
\varphi(x, z, t)=\operatorname{Re} \sum_{m=-\infty}^{\infty} \Phi_{m}(z) \exp \left[i \omega_{m}(x-c t)\right]
$$

In (17), $\Phi_{m}(z)=\Phi_{m}$ is a function of the single independent variable $z$. It is an $m$-th harmonic function, while the exponential function is only a function of $x$-ct.

Accordingly, the governing equation of the entire system can be written in the following form:

$$
\begin{aligned}
& b_{i 1} \frac{d^{2} Q_{i m}}{d z^{2}}+b_{i 2} Q_{i m}+b_{i 3} \frac{d R_{i m}}{d z}=0 \\
& c_{i 1} \frac{d^{2} R_{i m}}{d z^{2}}+c_{i 2} R_{i m}+c_{i 3} \frac{d Q_{i m}}{d z}=0
\end{aligned}
$$


The parameters in the above equations are $(i=1 \sim 8)$

$$
\begin{aligned}
& b_{i 1}=G_{i}^{*}, \\
& b_{i 2}=-\left(\omega_{m}\right)^{2} \frac{2 G_{i}^{*}\left(1-v_{i}\right)}{1-2 v_{i}}+\left(\omega_{m}\right)^{2} c^{2} \rho_{s} \\
& b_{i 3}=i \omega_{m}\left(\frac{2 G_{i}^{*} v_{i}}{1-2 v_{i}}+G_{i}^{*}\right) \\
& c_{i 1}=\frac{2 G_{i}^{*}\left(1-v_{i}\right)}{1-2 v_{i}} \\
& c_{i 2}=-w_{m}^{2} G_{i}^{*}+w_{m}^{2} c^{2} \rho_{s} \\
& c_{i 3}=i \omega_{m}\left(\frac{2 G_{i}^{*} \nu_{i}}{1-2 v_{i}}+G_{i}^{*}\right) \\
& G_{i}^{*}=G_{i}(1+2 \delta i)
\end{aligned}
$$

The general solution of the governing equation may be expressed as follows:

$$
\begin{aligned}
& Q_{i m}=\sum_{j=1}^{4} A_{i j m} \exp \left(q_{i j} z\right) \\
& R_{i m}=\sum_{j=1}^{4} r_{i j} A_{i j m} \exp \left(q_{i j} z\right)
\end{aligned}
$$

After simplification,

$$
\begin{array}{r}
\sum_{j=1}^{4}\left[b_{i 1}\left(q_{i j}\right)^{2}+b_{i 2}+b_{i 3} r_{i j} q_{i j}\right] A_{i j m}=0 \\
\sum_{j=1}^{4}\left[c_{i 1} r_{i j}\left(q_{i j}\right)^{2}+c_{i 2} r_{i j}+c_{i 3} q_{i j}\right] A_{i j m}=0
\end{array}
$$

where $r_{i j}=-\left(b_{i 1}\left(q_{i j}\right)^{2}+b_{i 2}\right) / q_{i j} b_{i 3}$, and $q_{i j}(j=1 \sim 4)$ are the roots of the 4 th-order polynomials in

$$
b_{i 1} c_{i 1}(q)^{4}+\left(b_{i 2} c_{i 2}-b_{i 3} c_{i 3}+b_{i 1} c_{i 2}\right)(q)^{2}+b_{i 2} c_{i 2}=0
$$

The solutions (roots) can be obtained through numerical methods (e.g., MATLAB program).

2.4.2. Boundary Conditions and Solution. In order to solve the governing equation, it is necessary to obtain the integration constant $A_{i j m}(i=1 \sim 8, j=1 \sim 4)$.

At the top of the upper surface layer $(z=0): \tau_{1 x z}=k F$ ( $k$ is coefficient of rolling friction), $\sigma_{1 z}=F$.

At the bottom of the upper surface layer $\left(z=H_{1}\right)$, the boundary condition of the displacement is $\zeta_{1 x}=\delta_{1}$ and $\xi_{1 z}=\delta_{2}$.
Then, the group of equations for the boundary condition can be written as

$$
\begin{aligned}
& \sum_{j=1}^{4}\left(q_{1 j}+i \omega_{m} r_{1 j}\right) A_{1 j m}=k \cdot F_{m} \\
& \sum_{j=1}^{4}\left[-\left(2 G_{1}^{*} \frac{1-\nu_{1}}{1-2 \nu_{1}}\right) q_{1 j} r_{1 j}-\left(i \omega_{m}\right)\left(2 G_{1}^{*} \frac{\nu_{1}}{1-2 \nu_{1}}\right)\right] \\
& \cdot A_{1 j m}=F_{m} \\
& \sum_{j=1}^{4} A_{1 j m} \exp \left(q_{1 j} H_{1}\right)=\delta_{1} \\
& \sum_{j=1}^{4} r_{1 j} A_{1 j m} \exp \left(q_{1 j} H_{1}\right)=\delta_{2} \\
& \sum_{j=1}^{4}\left[-\left(2 G_{1}^{*} \frac{1-\nu_{1}}{1-2 \nu_{1}}\right) q_{1 j} r_{1 j}-\left(i \omega_{m}\right)\left(2 G_{1}^{*} \frac{\nu_{1}}{1-2 \nu_{1}}\right)\right] \\
& \cdot A_{1 j m} \exp \left(q_{1 j} H_{1}\right)=\sigma_{H_{1}} \\
& \sum_{j=1}^{4} G_{1}^{*}\left(q_{1 j}+i \omega_{m} r_{1 j}\right) A_{1 j m} \exp \left(q_{1 j} H_{1}\right)=\chi_{H_{1}}
\end{aligned}
$$

The boundary conditions for the middle surface layer, the lower surface layer, the upper base layer, the middle base layer, the lower base layer, and the upper subgrade $(i=2 \sim 7)$ are

$$
\begin{aligned}
& \sum_{j=1}^{4} A_{i j m} \exp \left(q_{i j} H_{i-1}\right)=\delta_{i-1} \\
& \sum_{j=1}^{4} r_{i j} A_{i j m} \exp \left(q_{i j} H_{i-1}\right)=\delta_{i} \\
& \sum_{j=1}^{4} G_{i}^{*}\left(q_{i j}+i \omega_{m} r_{i j}\right) A_{i j m} \exp \left(q_{i j} H_{i-1}\right)=\chi_{H_{i-1}} \\
& \sum_{j=1}^{4}\left[-\left(2 G_{i}^{*} \frac{1-v_{i}}{1-2 v_{i}}\right) q_{i j} r_{i j}-\left(i \omega_{m}\right)\left(2 G_{i}^{*} \frac{v_{i}}{1-2 v_{i}}\right)\right] \\
& \cdot A_{i j m} \exp \left(q_{i j} H_{i-1}\right)=\sigma_{H_{i-1}} \\
& \sum_{j=1}^{4} A_{i j m} \exp \left(q_{i j} H_{i}\right)=\delta_{i+1} \\
& \sum_{j=1}^{4} r_{i j} A_{i j m} \exp \left(q_{i j} H_{i}\right)=\delta_{i+2} \\
& \sum_{j=1}^{4} G_{i}^{*}\left(q_{i j}+i \omega_{m} r_{i j}\right) A_{i j m} \exp \left(q_{i j} H_{i}\right)=\chi_{H_{i}}
\end{aligned}
$$




$$
\begin{aligned}
& \sum_{j=1}^{4}\left[-\left(2 G_{i}^{*} \frac{1-v_{i}}{1-2 v_{i}}\right) q_{i j} r_{i j}-\left(i \omega_{m}\right)\left(2 G_{i}^{*} \frac{v_{i}}{1-2 v_{i}}\right)\right] \\
& \cdot A_{i j m} \exp \left(q_{i j} H_{i}\right)=\sigma_{H_{i}}
\end{aligned}
$$

In the lower subgrade model, the boundary conditions are listed as follows.

At the interface between the lower subgrade and upper subgrade $\left(z=H_{7}\right)$, the boundary conditions for the displacements are $\xi_{x}=\delta_{71}$ and $\xi_{z}=\delta_{72}$.

At the interface between the lower subgrade and upper subgrade $\left(z=H_{7}\right)$, the boundary conditions for the stress are $\tau_{x z}=\chi_{H 7}$ and $\sigma_{z}\left(H_{4}\right)=\sigma_{H 7}$.

At the bottom of the lower subgrade $\left(z=H_{8}\right)$, the boundary conditions of the displacements are $\zeta_{x}=0$ and $\zeta_{z}=0$. Then, a group of equations for the corresponding boundary conditions can be written as

$$
\begin{aligned}
& \sum_{j=1}^{4} A_{8 j m} \exp \left(q_{8 j} H_{7}\right)=\delta_{71} \\
& \sum_{j=1}^{4} r_{8 j} A_{8 j m} \exp \left(q_{8 j} H_{7}\right)=\delta_{72} \\
& \sum_{j=1}^{4} G_{8}^{*}\left(q_{8 j}+i \omega_{m} r_{8 j}\right) A_{8 j m} \exp \left(q_{8 j} H_{7}\right)=\chi_{H_{7}} \\
& \sum_{j=1}^{4}\left[-\left(2 G_{8}^{*} \frac{1-v_{8}}{1-2 v_{8}}\right) q_{8 j} r_{8 j}-\left(i \omega_{m}\right)\left(2 G_{8}^{*} \frac{\nu_{8}}{1-2 \nu_{8}}\right)\right] \\
& \cdot A_{8 j m} \exp \left(q_{8 j} H_{7}\right)=\sigma_{H_{7}}
\end{aligned}
$$$$
\begin{aligned}
& \tau_{i x z}(x, z, t)=-\operatorname{Re} \sum_{m=-\infty}^{\infty}\left[\sum_{j=1}^{4} G_{i}^{*}\left(q_{i j}+i \omega_{m} r_{i j}\right) A_{i j m} \exp \left(q_{i j} z\right)\right] \exp \left[i \omega_{m}(x-c t)\right] \\
& \sigma_{i z}(x, z, t)=\operatorname{Re} \sum_{m=-\infty}^{\infty}\left\{\sum_{j=1}^{4}\left[-\left(2 G_{i}^{*} \frac{1-v_{i}}{1-2 v_{i}}\right) q_{i j} r_{i j}-i \omega_{m}\left(2 G_{i}^{*} \frac{v_{i}}{1-2 \nu_{i}}\right)\right] A_{i j m} \exp \left(q_{i j} z\right)\right\} \exp \left[i \omega_{m}(x-c t)\right] \\
& \sigma_{i x}(x, z, t)=\operatorname{Re} \sum_{m=-\infty}^{\infty}\left\{\sum_{j=1}^{4}\left[-\left(2 G_{i}^{*} \frac{v_{i}}{1-2 v_{i}}\right) q_{i j} r_{i j}-i \omega_{m}\left(2 G_{i}^{*} \frac{1-v_{i}}{1-2 v_{i}}\right)\right] A_{i j m} \exp \left(q_{i j} z\right)\right\} \exp \left[i \omega_{m}(x-c t)\right]
\end{aligned}
$$

The expressions for the vertical normal stress and vertical normal strain acting on the pavement system under the halfsinusoidal impulsive load are

$$
\left.\left.\cdot q_{i j} r_{i j}-i \omega_{m}\left(2 G_{i}^{*} \frac{v_{i}}{1-2 v_{i}}\right)\right] \bar{A}_{i j m} \exp \left(q_{i j} z\right)\right\} \exp \left[i \omega_{m} t\right]
$$

$$
\begin{array}{cc}
\bar{\sigma}_{i z}(z, t) & \bar{\varepsilon}_{i z}(z, t) \\
=\operatorname{Re} \sum_{m=-\infty}^{\infty}\left\{\sum _ { j = 1 } ^ { 4 } \left[-\left(2 G_{i}^{*} \frac{1-v_{i}}{1-2 v_{i}}\right)\right.\right. & =\operatorname{Re} \sum_{m=-\infty}^{\infty}\left\{\sum _ { j = 1 } ^ { 4 } \left[-\left(2 \frac{1-v_{i}}{1-2 v_{i}}\right)\right.\right.
\end{array}
$$

In addition, the expressions of the shear stress and the positive stress are

For all the groups of equations of the boundary conditions shown above, the numerical methods can be used to obtain the displacement $\left(\delta_{i x}\right.$ and $\left.\delta_{i y}\right)$, the positive stress $\left(\sigma_{H i}\right)$, and into the general expressions for the corresponding dynamic governing equations of the subgrade pavement system under a moving load. The solutions for the displacements can be expressed of the form

$$
\begin{aligned}
& \xi_{i x}(x, z, t)=\operatorname{Re} \sum_{m=-\infty}^{\infty}\left[\sum_{j=1}^{4} A_{i j m} \exp \left(q_{i j} z\right)\right] \\
& \cdot \exp \left[i \omega_{m}(x-c t)\right] \\
& \xi_{i z}(x, z, t)=\operatorname{Re} \sum_{m=-\infty}^{\infty}\left[\sum_{j=1}^{4} r_{i j} A_{i j m} \exp \left(q_{i j} z\right)\right] \\
& \cdot \exp \left[i \omega_{m}(x-c t)\right]
\end{aligned}
$$

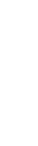




$$
\left.\left.\cdot q_{i j} r_{i j}-i \omega_{m}\left(2 \frac{v_{i}}{1-2 v_{i}}\right)\right] \bar{A}_{i j m} \exp \left(q_{i j} z\right)\right\} \exp \left[i \omega_{m} t\right]
$$

The expressions for the vertical normal stress and vertical normal strain acting on the pavement system under the triangular load are

$$
\begin{aligned}
& \overline{\bar{\sigma}}_{i z}(z, t) \\
& =\operatorname{Re} \sum_{m=-\infty}^{\infty}\left\{\sum _ { j = 1 } ^ { 4 } \left[-\left(2 G_{i}^{*} \frac{1-v_{i}}{1-2 v_{i}}\right)\right.\right. \\
& \left.\left.\cdot q_{i j} r_{i j}-i \omega_{m}\left(2 G_{i}^{*} \frac{v_{i}}{1-2 v_{i}}\right)\right] \overline{\bar{A}}_{i j m} \exp \left(q_{i j} z\right)\right\} \exp \left[i \omega_{m} t\right] \\
& \overline{\bar{\varepsilon}}_{i z}(z, t) \\
& =\operatorname{Re} \sum_{m=-\infty}^{\infty}\left\{\sum _ { j = 1 } ^ { 4 } \left[-\left(2 \frac{1-v_{i}}{1-2 v_{i}}\right)\right.\right. \\
& \left.\left.\cdot q_{i j} r_{i j}-i \omega_{m}\left(2 \frac{v_{i}}{1-2 v_{i}}\right)\right] \overline{\bar{A}}_{i j m} \exp \left(q_{i j} z\right)\right\} \exp \left[i \omega_{m} t\right]
\end{aligned}
$$

The expressions for the vertical normal stress and vertical normal strain acting on the pavement system under the vertical stepwise load are

$$
\begin{aligned}
& \overline{\overline{\bar{\sigma}}}_{i z}(z, t) \\
& =\operatorname{Re}_{m=-\infty}^{\infty}\left\{\sum _ { j = 1 } ^ { 4 } \left[-\left(2 G_{i}^{*} \frac{1-v_{i}}{1-2 v_{i}}\right)\right.\right. \\
& \left.\left.\cdot q_{i j} r_{i j}-i \omega_{m}\left(2 G_{i}^{*} \frac{v_{i}}{1-2 v_{i}}\right)\right] \overline{\bar{A}}_{i j m} \exp \left(q_{i j} z\right)\right\} \exp \left[i \omega_{m} t\right] \\
& \overline{\bar{\varepsilon}}_{i z}(z, t) \\
& =\operatorname{Re} \sum_{m=-\infty}^{\infty}\left\{\sum _ { j = 1 } ^ { 4 } \left[-\left(2 \frac{1-v_{i}}{1-2 v_{i}}\right)\right.\right. \\
& \left.\left.\cdot q_{i j} r_{i j}-i \omega_{m}\left(2 \frac{v_{i}}{1-2 \nu_{i}}\right)\right] \overline{\bar{A}}_{i j m} \exp \left(q_{i j} z\right)\right\} \exp \left[i \omega_{m} t\right]
\end{aligned}
$$

\section{Evaluation Method for Rutting and Fatigue Life of Asphalt Pavement}

There were four loading patterns in this paper (i.e., halfsinusoidal load, triangular load, vertical stepwise load, and moving load (in two-dimensional situations, moving load could be simplified into strip load, which was shown in Figure 2)). The moving load can most accurately represent the actual traffic loading pattern. The three other load functions (half-sinusoidal load, triangular load, and vertical stepwise load) only simplify the moving load. In order to establish the equivalence and conversion relationship between the three load functions and the moving load pattern, this paper utilized the rutting of pavement and fatigue life as control indices for equivalence calculation. Hence, the application periods (time) and amplitudes (load peak value) under the three load conditions have been confirmed.

3.1. Method for Rutting Calculation. Asphalt mixture is a temperature-sensitive material, and its road performance is closely related to its temperature sensitivity. Rutting usually occurs easily under high temperatures and changes with temperatures. Being a composite material, asphalt mixture is a classic complex of elasticity, viscosity, and plasticity. On the one hand, under low temperatures and a small deformation range, its behavior is close to a linear elastic body; on the other hand, under high temperatures and a wide deformation range, it behaves as a viscoplastic body. In the transition zone under normal temperatures, it is a normal viscoelastic body. Owing to vehicle loading, the properties of the asphalt mixture become highly complex. In the actual application situations, it is usually an inelastic body, with irreversible deformation after unloading. With reference to the pavement design guidelines in AASHTO [10], the following can be obtained:

$$
\begin{aligned}
\log \left(\frac{\varepsilon_{p}}{\varepsilon_{r}}\right)= & -3.7498+0.4262 \log (N) \\
& +2.02755 \log (T)
\end{aligned}
$$

$\varepsilon_{\mathrm{p}}$ is the cumulative permanent deformation (units: -), $\varepsilon_{\mathrm{r}}$ is the recovery strain (units: -),

$N$ is the number of axle loadings at cumulative permanent deformation (units: -),

$T$ is the temperature at the surface of the asphalt pavement (units: ${ }^{\circ} \mathrm{C}$ ).

$$
R D=\sum_{i=1}^{N}\left(\varepsilon_{p}\right)_{i} \Delta h_{i}
$$

$\mathrm{RD}$ is the rutting depth on asphalt-concrete pavement surface layer (units: $\mathrm{m}$ ),

$N$ is the number of asphalt layers (units: -),

$\left(\varepsilon_{\mathrm{p}}\right)_{\mathrm{i}}$ is the vertical plastic strain in the middle of the $i$-th asphalt layer (units: -),

$\Delta h_{\mathrm{i}}$ is the thickness of the $i$-th asphalt layer (units: $\mathrm{m}$ ).

3.2. Method for Fatigue Life Calculation. Overloading or insufficient structural strength of the surface layer usually causes an enormous tensile strain. The following can be obtained using the pavement design guidelines in AASHTO [10] to define the fatigue life:

$$
N_{f}=0.00432 \cdot k \cdot C \cdot\left(\frac{1}{\varepsilon_{t}}\right)^{3.9492}\left(\frac{1}{E}\right)^{1.281}
$$


$N_{\mathrm{f}}$ is the number of axle loadings (units: -),

$E$ is the elastic modulus (units: $\mathrm{MPa}$ ),

$\varepsilon_{\mathrm{t}}$ is the tensile strain at the surface of the asphalt pavement (units: -),

$C$ is the coefficient associated with the asphalt mixture volume (units: -),

$k$ is the coefficient associated with the asphalt mixture thickness(units: -).

\section{Model Validation and Analysis}

4.1. Model Validation. This paper compared the theoretical calculation results to those from numerical simulations to configure the application periods of the three load conditions (half-sinusoidal load, triangular load, and vertical stepwise load). Their respective amplitudes were obtained through the comparison between the rutting under the three load conditions and the rutting under the moving traffic load. With the new load amplitudes and application periods, mutual conversion relationships were established to confirm that the three load conditions can provide a better simulation of the dynamic responses of asphalt pavements under the moving traffic load. The structure of the asphalt pavement adopted in the analysis is shown in Figure 3.The parameters of the asphalt mixture are shown in the Tables 1,2 , and 3 $[27,28]$.

The pavement structure [29] size was $6 \mathrm{~m} \times 3 \mathrm{~m} \times 3$ $\mathrm{m}$ in length, width, and height, as shown in Figure 4 . The model adopted the form of C3D8R unit, and the surface layer divided a grid every $1 \mathrm{~cm}$ along the depth direction. There were 266400 elements in the surface layer. The base layer divided a grid every $2 \mathrm{~cm}$ along the depth direction, and the model had a total of 454,400 elements, as shown in Figure 5.

For a scenario with a vehicle speed $c=20 \mathrm{~m} / \mathrm{s}$, a tire pressure $F=0.7 \mathrm{MPa}$, a rolling friction coefficient $k=0.02$, and temperature $40^{\circ} \mathrm{C}$, the dynamic response of the structure of the asphalt pavement and the rutting of the asphalt pavement were calculated with the theoretical analytic solutions established in this paper and the finite software ABAQUS. The results were shown in Figure 6. A rolling friction coefficient $k=0.02, \mathrm{ALN}=10000$, and the calculation results of $\mathrm{RD}$ for different temperatures of $20^{\circ} \mathrm{C}, 30^{\circ} \mathrm{C}, 40^{\circ} \mathrm{C}, 50^{\circ} \mathrm{C}$, and $60^{\circ} \mathrm{C}$ were shown in Figure 7.

As shown in Figures 6 and 7, the theoretical calculation values and the finite calculation results agreed well for the rutting of the asphalt pavement under loading, proving the validity of the theoretical analytic solutions derived for the dynamic responses of the asphalt pavement under different loading patterns.

As shown in Figures 6 and 8, the calculated rutting of the asphalt pavement under the moving traffic load was 1.06, 1.31, and 1.35 times of those under the sinusoidal, triangular, and vertical stepwise load functions. This indicated that the sinusoidal load is capable of better simulating the moving traffic load whereas the triangular and vertical stepwise load functions result in certain errors in simulating the moving traffic load.

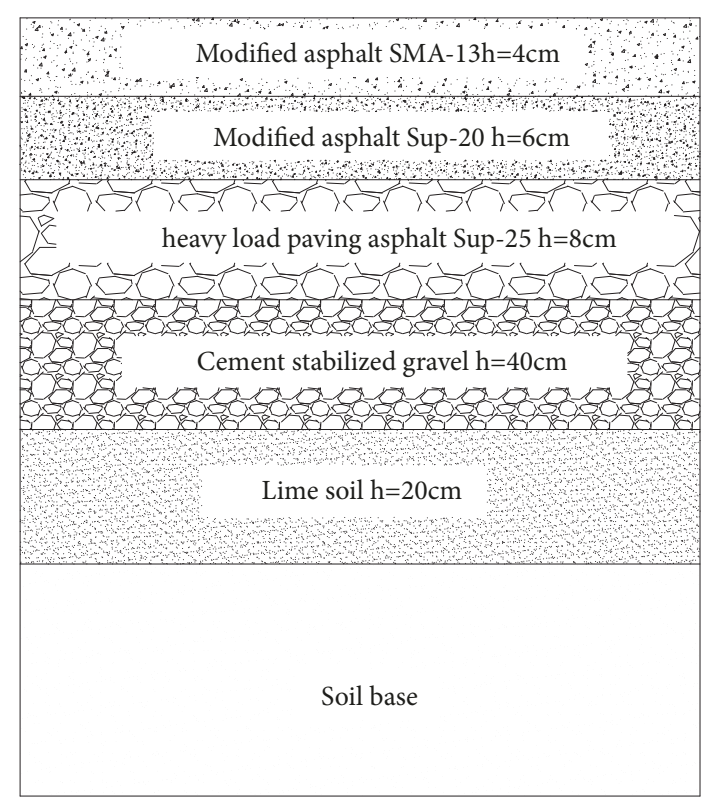

FIGURE 3: Structural patterns of semirigid base asphalt pavements.

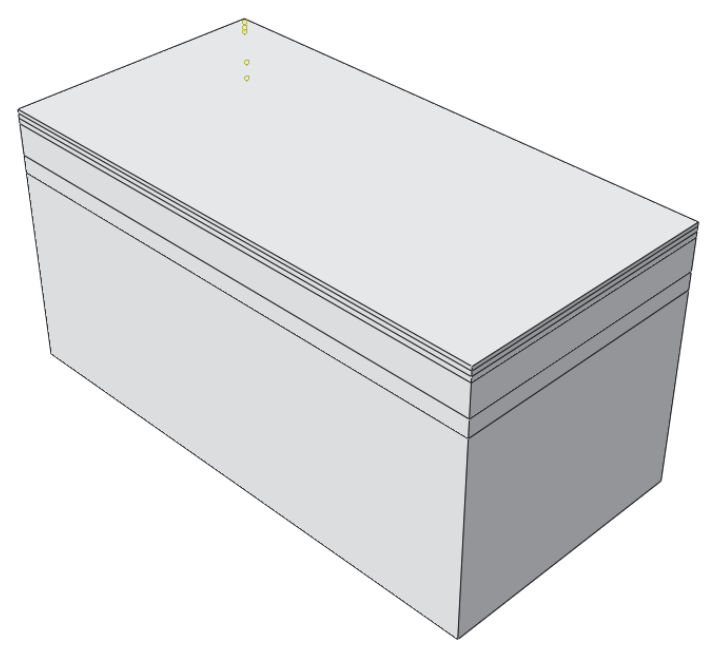

FIGURE 4: Three-dimensional model of asphalt pavement structure.

\subsection{Loading Equivalence}

4.2.1. Rutting as a Control Index. As all the three load conditions resulted in errors in simulating the moving traffic load, this paper improved the following two aspects of the three load conditions such that they can well simulate the moving traffic load. The first method to improve the load conditions was altering the amplitudes of the three load functions whilst keeping their periods unchanged to simulate the moving traffic load. The second method was to change the periods of the three load functions with their amplitudes unchanged

(a) Keeping the Load Periods Unchanged. The first change was intended to eliminate the errors in simulating the moving traffic load through varying the load amplitudes yet keeping 
TABLE 1: Elasticity parameters of the asphalt mixture.

\begin{tabular}{lccc}
\hline Asphaltic layers & Temperature $\left({ }^{\circ} \mathrm{C}\right)$ & Elastic modulus $(\mathrm{MPa})$ & Poisson ratio \\
\hline & 20 & 870 & 0.25 \\
SMA-13 & 30 & 520 & 0.30 \\
& 40 & 554 & 0.35 \\
& 50 & 530 & 0.40 \\
& 60 & 526 & 0.45 \\
Sup20 & 20 & 910 & 0.25 \\
& 30 & 600 & 0.30 \\
& 40 & 440 & 0.35 \\
Sup25 & 50 & 380 & 0.40 \\
& 60 & 1031 & 0.45 \\
& 20 & 900 & 0.25 \\
& 30 & 710 & 0.30 \\
& 40 & 500 & 0.35 \\
\end{tabular}

TABLE 2: Elasticity parameters of materials.

\begin{tabular}{lccc}
\hline Materials & Elastic modulus $(\mathrm{MPa})$ & Poisson ratio & Density $\left(\mathrm{kg} / \mathrm{m}^{3}\right)$ \\
\hline Asphalt mixture & See Table 1 & See Table 1 & 2300 \\
Cement stabilized gravel & 1200 & 0.20 & 2200 \\
Lime soil & 300 & 0.30 & 2100 \\
Soil base & 45 & 0.40 & 1800 \\
\hline
\end{tabular}

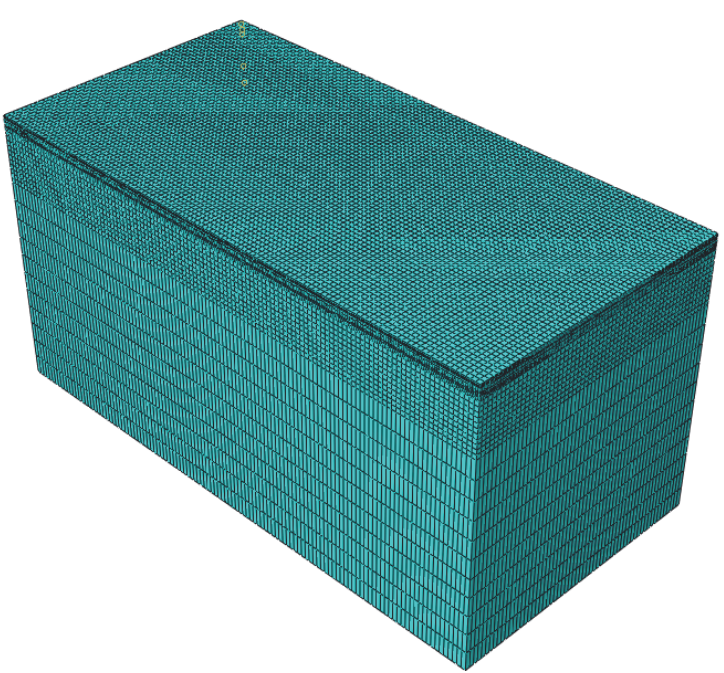

Figure 5: Three-dimensional finite element meshing of asphalt pavement structure.

the load periods unchanged. The calculation results are as shown in Figure 9 (ALN is the axle load number).

As shown in Figure 9, after amplitude modification, the new sinusoidal, triangular, and vertical stepwise load functions (increasing the amplitudes of the three load functions by $1.06,1.31$, and 1.35 times, resp.) resulted in rutting almost identical to that from the moving traffic load. This suggested that, while maintaining the same periods, amplitude modification of the three load functions can bring about better simulation of the moving traffic load and eliminate the simulation errors.

(b) Keeping the Load Amplitude Unchanged. By varying the load periods yet keeping the load amplitudes unchanged, the errors in simulating the moving traffic load are eliminated. The calculation results are as shown in Figures 10, 11, and 12.

As shown in Figure 10, with longer sinusoidal load periods, the rutting of the asphalt pavement was greater. When the period is increased by 1.07 times, the rutting thereby calculated was basically the same as that calculated under the moving traffic load. This demonstrated that when the sinusoidal load function is employed to simulate the moving traffic load, better simulation results can be achieved and the simulation errors can be reduced by increasing the load period (1.07 times) yet keeping the load amplitude unchanged.

As shown in Figure 11, with longer triangular load periods, the rutting of the asphalt pavement is greater. When the period was increased 2.23 times, the rutting thereby calculated and that under the moving traffic load are more or less identical. This suggests that when the triangular load function was applied to simulate the moving traffic load, better simulation results can be achieved and the simulation errors can be eliminated by increasing 2.23 times of the load period, while keeping amplitude fixed.

As shown in Figure 12, the rutting of the asphalt pavement increases with vertical stepwise load periods. As the period is 
TABLE 3: Creep parameters of the asphalt mixture.

\begin{tabular}{|c|c|c|c|c|c|}
\hline Asphaltic layers & Temperature $\left({ }^{\circ} \mathrm{C}\right)$ & A & $n$ & $m$ & $R^{2}$ \\
\hline \multirow{5}{*}{ SMA-13 } & 20 & $6.536 \mathrm{E}-11$ & 0.937 & -0.592 & 0.9326 \\
\hline & 30 & $3.325 \mathrm{E}-9$ & 0.862 & -0.587 & 0.9459 \\
\hline & 40 & $1.446 \mathrm{E}-8$ & 0.792 & -0.577 & 0.9420 \\
\hline & 50 & $1.39 \mathrm{E}-6$ & 0.414 & -0.525 & 0.9244 \\
\hline & 60 & $1.464 \mathrm{E}-5$ & 0.336 & -0.502 & 0.9049 \\
\hline \multirow{5}{*}{ Sup20 } & 20 & $4.58 \mathrm{E}-11$ & 0.944 & -0.596 & 0.9264 \\
\hline & 30 & $2.461 \mathrm{E}-9$ & 0.796 & -0.585 & 0.9227 \\
\hline & 40 & $3.673 \mathrm{E}-8$ & 0.773 & -0.570 & 0.9364 \\
\hline & 50 & $4.802 \mathrm{E}-6$ & 0.595 & -0.532 & 0.8494 \\
\hline & 60 & $7.778 \mathrm{E}-5$ & 0.384 & -0.441 & 0.9138 \\
\hline \multirow{5}{*}{ Sup25 } & 20 & $4.59 \mathrm{E}-11$ & 0.922 & -0.581 & 0.9377 \\
\hline & 30 & $3.461 \mathrm{E}-9$ & 0.859 & -0.576 & 0.9208 \\
\hline & 40 & $1.956 \mathrm{E}-8$ & 0.830 & -0.562 & 0.9063 \\
\hline & 50 & $1.200 \mathrm{E}-6$ & 0.322 & -0.522 & 0.8015 \\
\hline & 60 & $3.755 \mathrm{E}-5$ & 0.210 & -0.418 & 0.8994 \\
\hline
\end{tabular}

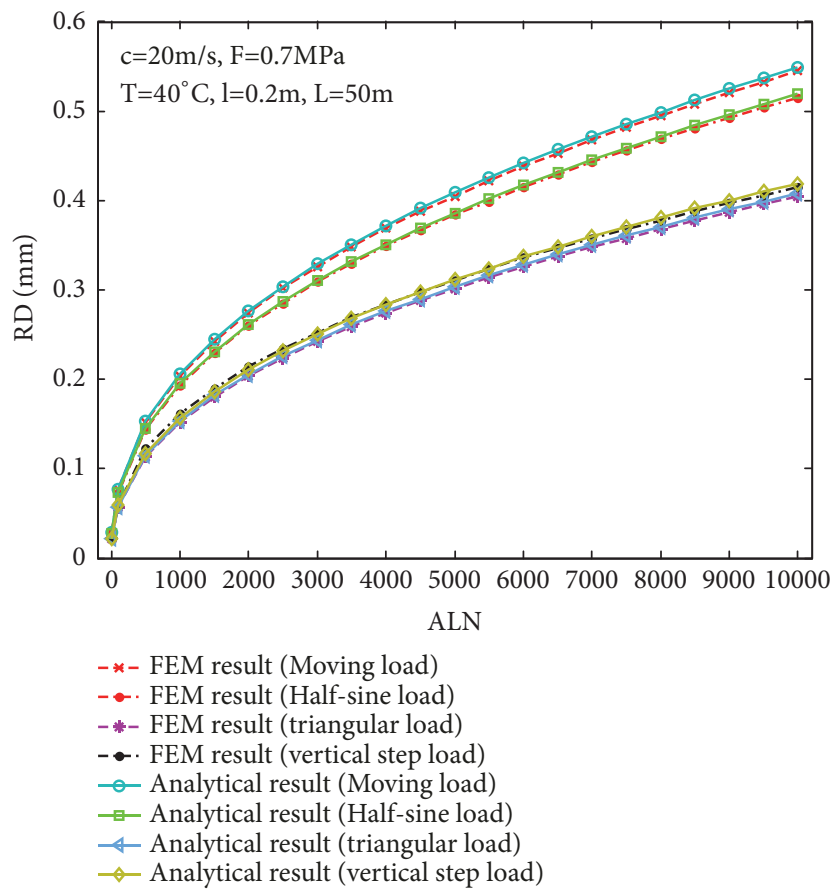

FIGURE 6: Comparison of rutting depths of asphalt pavement under different load conditions.

increased 2.1 times, the rutting calculated is basically the same as that calculated under the moving traffic load. This suggests that when the vertical stepwise load function is applied in moving traffic load simulation, increasing 2.1 times of the load period but keeping the same load amplitude can provide better simulation results and reduce the simulation errors.

As shown by the above two methods, regardless of whether the load amplitudes or the load periods were altered, the moving traffic load was well simulated.

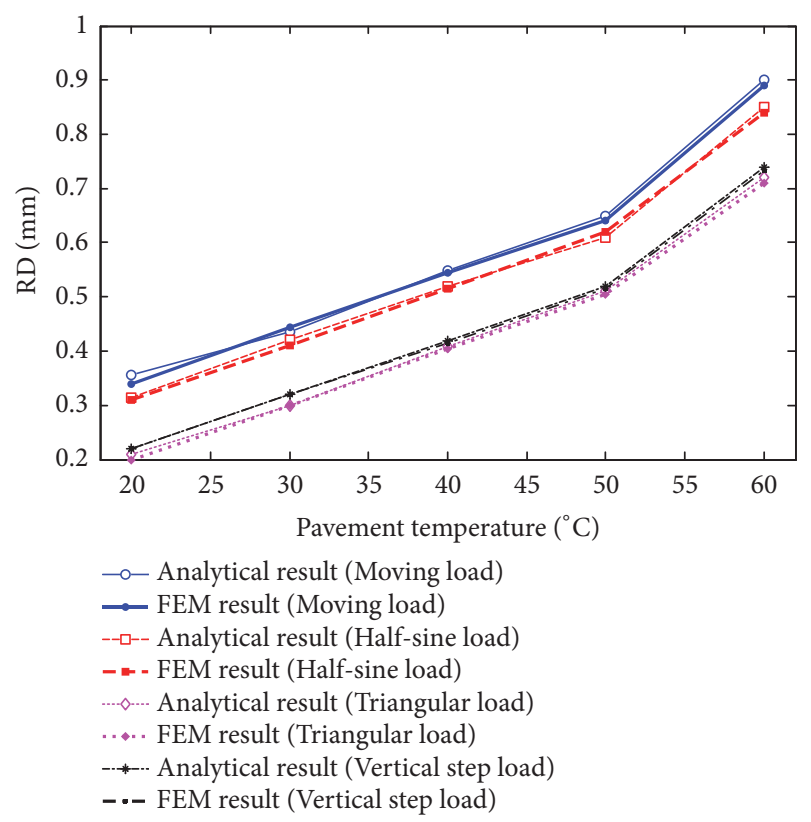

FIGURE 7: Comparison of rutting depths of asphalt pavement under different load conditions.

(c) Effects of Material Parameters on Load Periods and Amplitudes. From (34), (36), and (38), the responses of the pavement system are related to not only the load amplitudes, but also the material parameter of the system. The materials of the system were varied to analyze the effects of pavement material parameters on the multiple relationships between the load periods and amplitudes. The pavement structural pattern is as shown in Figure 13 and the pavement mixture parameters are as shown in Table 4.

For a scenario with a vehicle speed $c=20 \mathrm{~m} / \mathrm{s}$, a tire pressure $F=700000 \mathrm{~Pa}$, a rolling friction coefficient $k=0.02$, and temperature $15^{\circ} \mathrm{C}$, the dynamic response of the structure 
TABLE 4: Calculation parameters for asphaltic layers.

\begin{tabular}{lccr}
\hline Asphaltic layers & Elastic modulus $(\mathrm{MPa})$ & Density $\left(\mathrm{kg} / \mathrm{m}^{3}\right)$ & Poisson ratio \\
\hline AK-13A & 1200 & 2500 & 0.25 \\
AC-20C & 1835 & 2500 & 0.25 \\
AC-20F & 1800 & 2500 & 0.25 \\
Cement-stabilized gravel & 1500 & 2400 & 0.25 \\
Lime-fly-ash gravel & 1400 & 2000 & 0.25 \\
Lime soil & 550 & 1930 & 0.35 \\
Soil base & 48 & 1900 & 0.40 \\
\hline
\end{tabular}

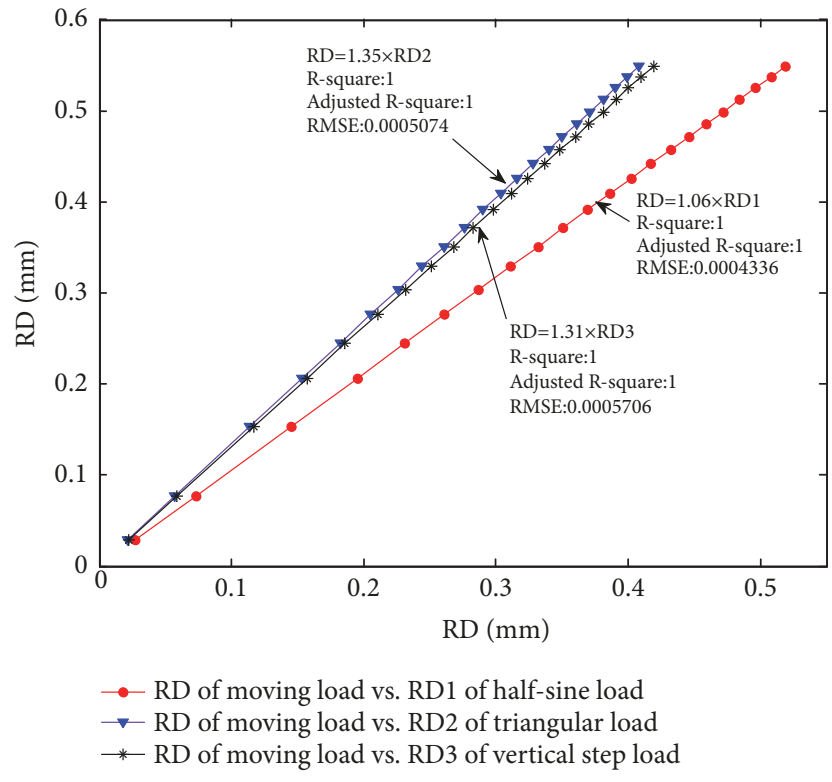

FIGURE 8: Relationships between rutting of asphalt pavement under the moving traffic load and the three load simulation conditions.

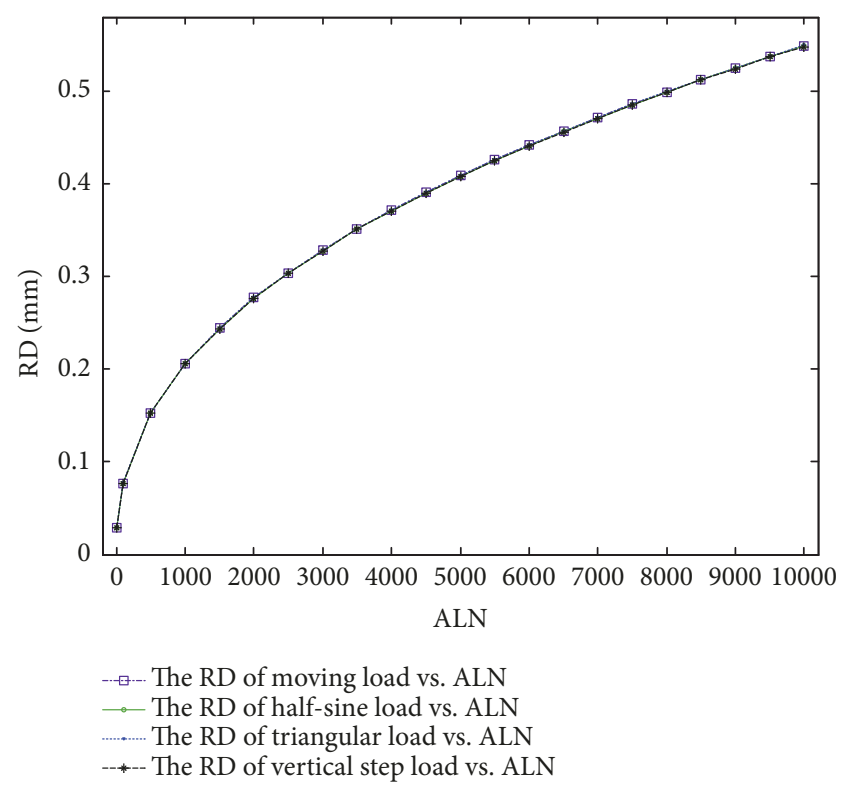

FIGURE 9: Rutting of asphalt pavement after varying the amplitudes of the three load conditions.

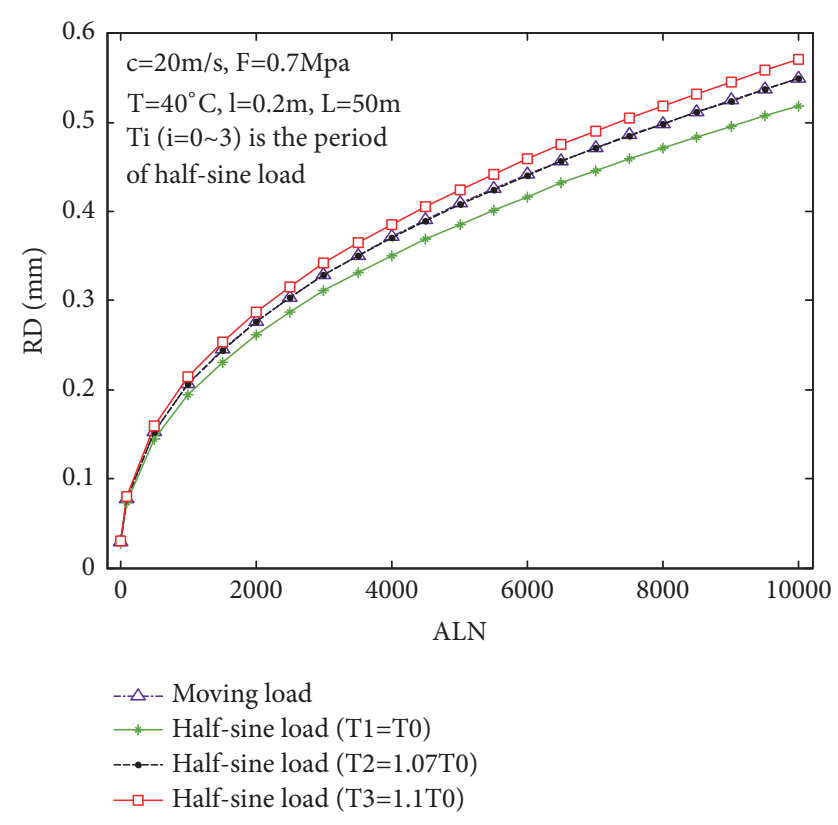

FIGURE 10: Rutting of asphalt pavement under sinusoidal load functions with different periods.

of the asphalt pavement and the rutting of the asphalt pavement were calculated with the theoretical analytic solutions established in this paper. The results are as shown in Figure 14.

Comparing Figures 14-17 with the previous Figures 9-12, it is found that, after changing the pavement materials, increasing the amplitudes of the three load functions by $1.06,1.31$, and 1.35 times of the load amplitudes of the halfsinusoidal, triangular and vertical stepwise load functions while keeping load periods unchanged allows good simulation of the moving traffic load. Moreover, when the load amplitudes are kept unchanged and the sinusoidal, triangular, and vertical stepwise load function periods are increased by $1.07,2.23$, and 2.1 times, respectively, a good simulation of the moving traffic load is achieved. Hence, changing the material parameters of the pavement has no effect on the multiple load-period relationships of the three load functions.

4.2.2. Pavement Fatigue Life as a Control Index. From (35), the relationship between the pavement fatigue life $N_{\mathrm{f}}$ and the tensile strain $\varepsilon_{\mathrm{t}}$ is an exponential function (Figure 18). Thus, for a fixed pavement structure, the pavement fatigue life is 


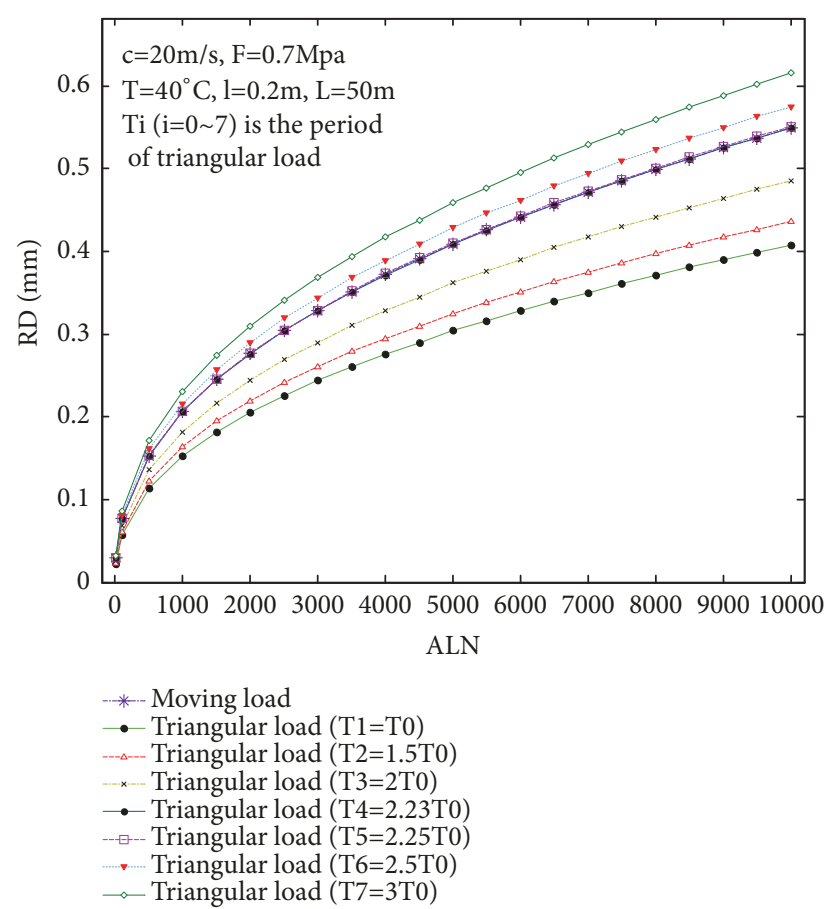

FIGURE 11: Rutting of asphalt pavement under triangular load functions with different periods.

TABLE 5: Calculated tensile strains under the different load functions.

\begin{tabular}{lc}
\hline Load types & Tension strain $\left(\varepsilon_{\mathrm{t}}\right)$ \\
\hline Moving traffic load & $8.28 \mathrm{E}-5$ \\
Half-sinusoidal load & $7.53 \mathrm{E}-5$ \\
Triangular load & $7.53 \mathrm{e}-5$ \\
Vertical stepwise load & $7.53 \mathrm{e}-5$ \\
\hline
\end{tabular}

solely associated with the tensile strain $\varepsilon_{\mathrm{t}}$ (the load acting on the pavement); that is,

$$
N_{f}=a \cdot \varepsilon_{t}^{-3.9492}
$$

where $a$ is a constant that needs to be determined.

For a scenario with a vehicle speed $c=20 \mathrm{~m} / \mathrm{s}$, a tire pressure $F=700000 \mathrm{~Pa}$, a rolling friction coefficient $k=0.02$, and temperature $15^{\circ} \mathrm{C}$, the dynamic response of the structure of the asphalt pavement was calculated with the theoretical analytic solutions established in this paper. The results are as shown in Table 5.

As shown in Table 5, the tensile strains on the pavement surface under the three load functions have the same values, suggesting that the tensile strains are only associated with the load size but not the loading patterns. The comparison revealed that the pavement surface tensile strain under the moving load was 1.1 times of that under the three load functions.

4.2.3. Combination of Rutting and Fatigue Life Indexes. As aforementioned, when the rutting of pavement was considered as the control index, for the unchanged load periods for

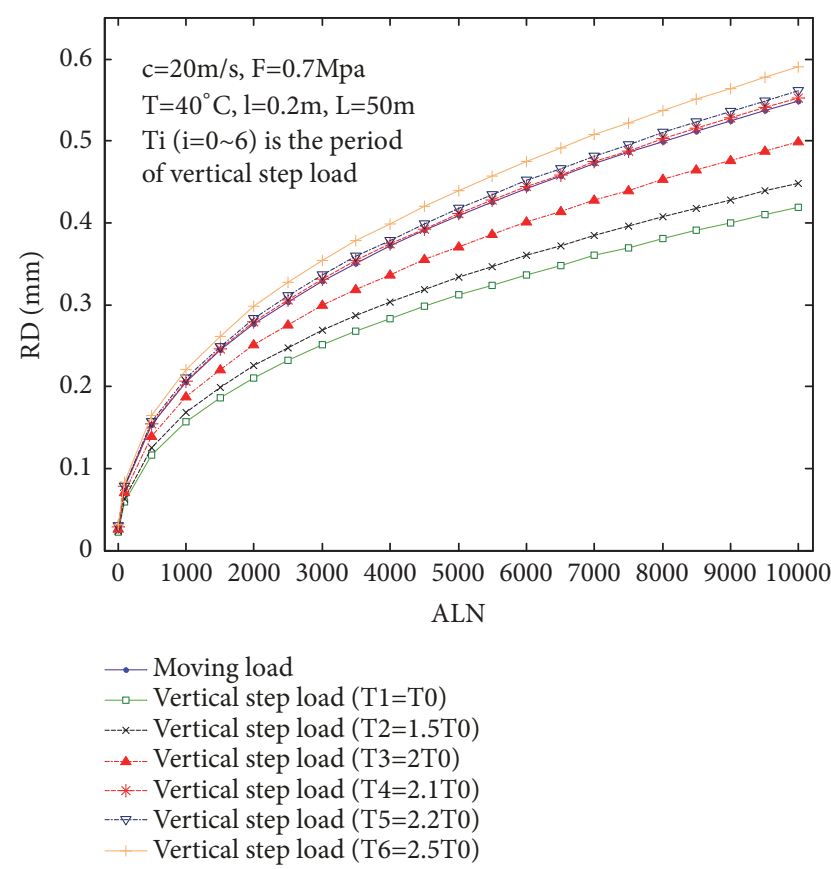

FIGURE 12: Rutting of asphalt pavement under vertical stepwise load functions with different periods.

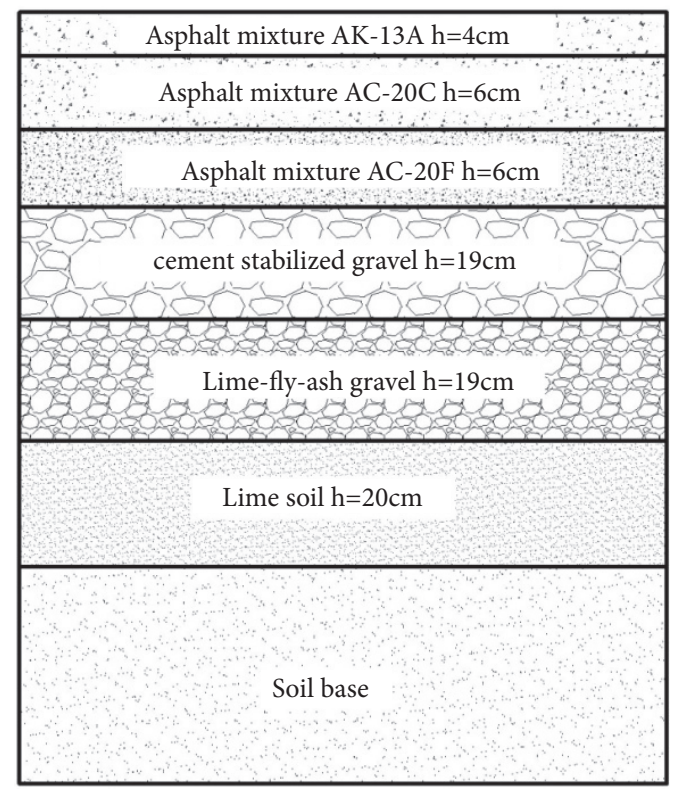

FIGURE 13: Asphalt pavement structure with multiasphaltic layers.

the four load conditions, the amplitude of the moving traffic load was 1.06, 1.31, and 1.35 times of the amplitude of the sinusoidal, triangular, and vertical stepwise load functions. When the load amplitudes were kept unchanged, the period of the moving traffic load was 1.07, 2.1, and 2.23 times the halfsinusoidal, triangular, and vertical stepwise load functions, respectively. On the other hand, when the fatigue life was employed as the control index, only the load amplitudes of the four load conditions were relevant, but not the load 
TABLE 6: Loading equivalence between various loading types in terms of the peak load values and the load periods.

\begin{tabular}{lcccc}
\hline Load types & The peak load values & Load periods & \multicolumn{2}{c}{ Indexes } \\
\hline Moving traffic load & $\mathrm{P}$ & $\mathrm{T}$ & Rutting & Fatigue life \\
Half-sinusoidal load & $1.1 \mathrm{P}$ & $1.03 \mathrm{~T}$ & Rutting & Fatigue life \\
Triangular load & $1.1 \mathrm{P}$ & $2.50 \mathrm{~T}$ & Rutting & Fatigue life \\
Vertical stepwise load & $1.1 \mathrm{P}$ & $2.74 \mathrm{~T}$ & Rutting & Fatigue life \\
\hline
\end{tabular}

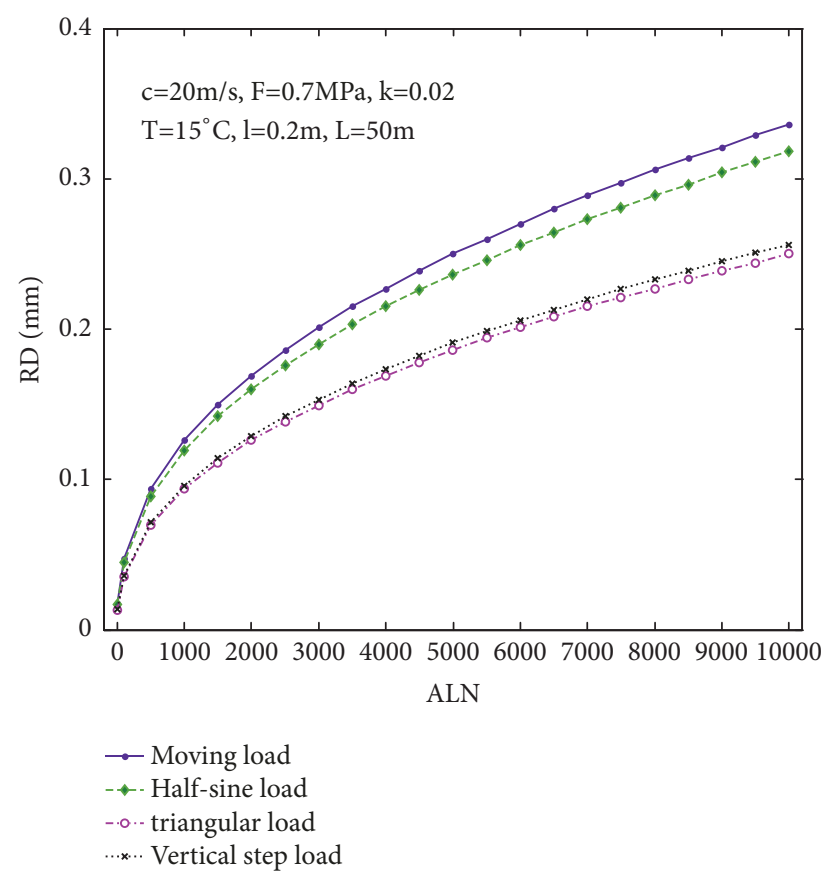

FIGURE 14: Comparison of rutting depth of asphalt pavement under different load conditions.

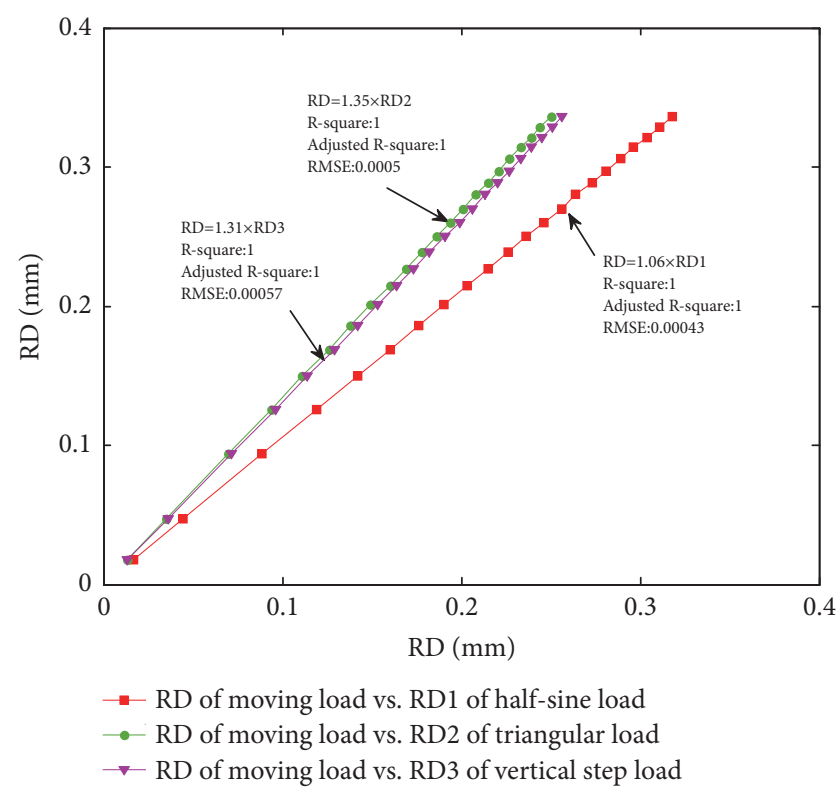

FIGURE 15: Relationship between rutting of asphalt pavement under the moving traffic load and that under the three load functions.

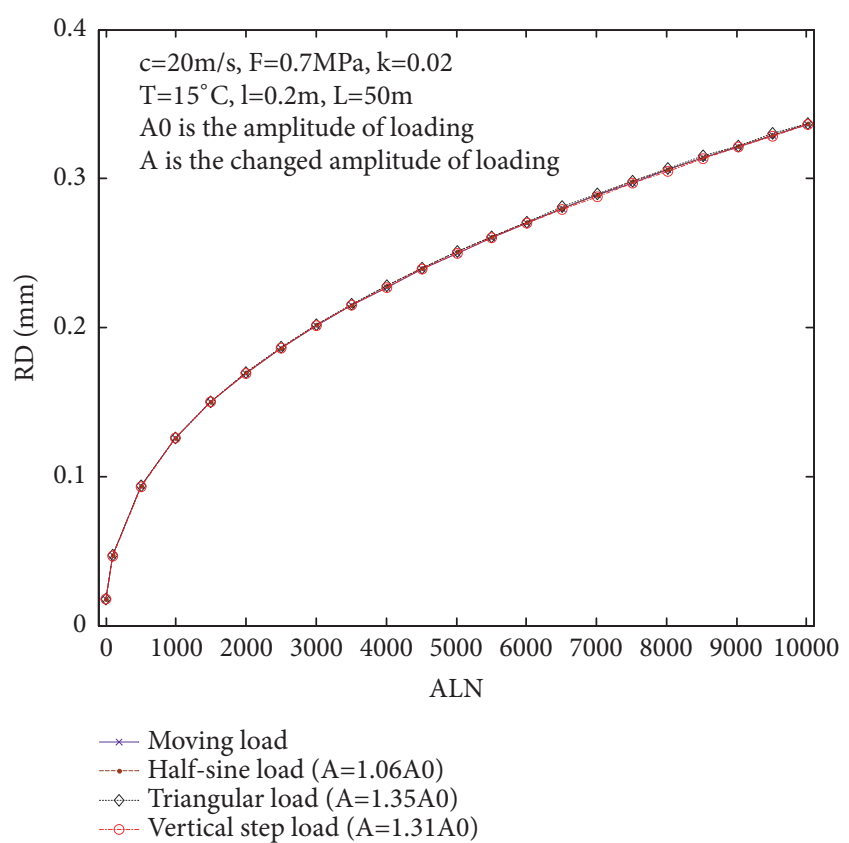

Figure 16: Comparison between rutting under the moving traffic load and that under the three load functions after load amplitude modification.

periods. Under the same peak loads, the tensile strains at the pavement base were identical for the sinusoidal, triangular, and vertical stepwise load functions. However, the pavement base tensile strain under the moving traffic load was twice that under the three load functions. Thus, in order to ensure the equivalent rutting and fatigue life under the four load conditions simultaneously, the relationship between the peak load values and the load periods was obtained through comparison during application and is shown in Table 6.

\section{Conclusions}

This paper derived the explicit analytic solutions to dynamic response of asphalt pavements under three impulsive load conditions and compared the results with the calculated results by the finite software ABAQUS to verify the validity of the explicit analytical solutions derived. This can provide theoretical supports for the treatment of rutting of asphalt pavement with theoretical bases, which is of practical importance to asphalt pavement projects. In order to establish the equivalence between four loading types (i.e., half-sinusoidal load, triangular load, vertical stepwise load, and moving 


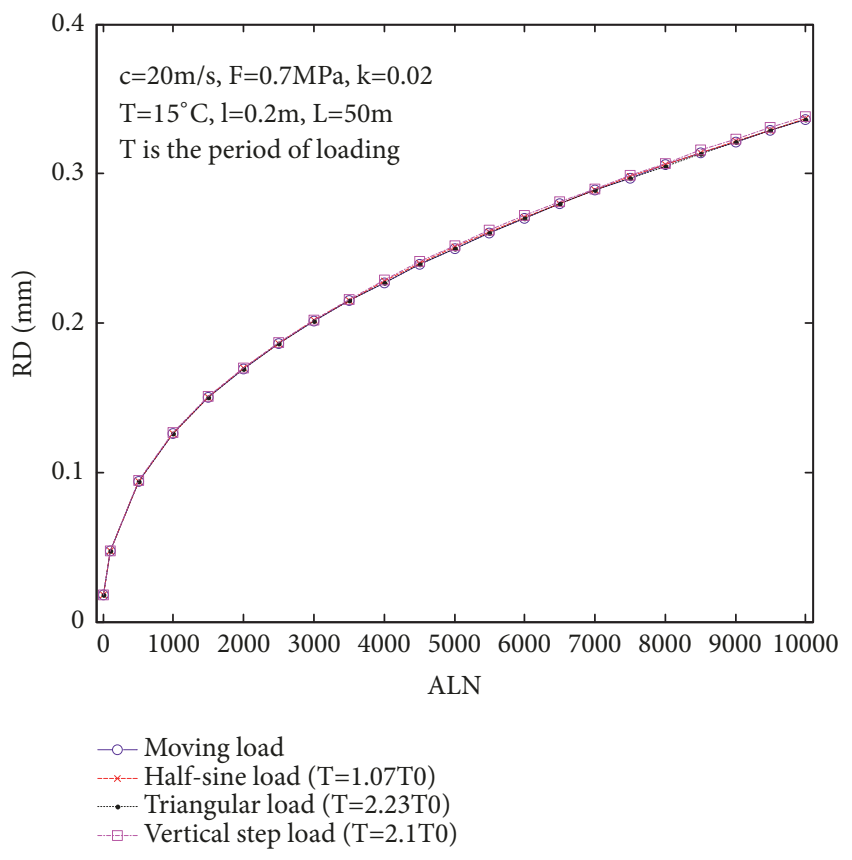

FIGURE 17: Comparison between rutting under the moving traffic load and that under the three load functions after load period modification.

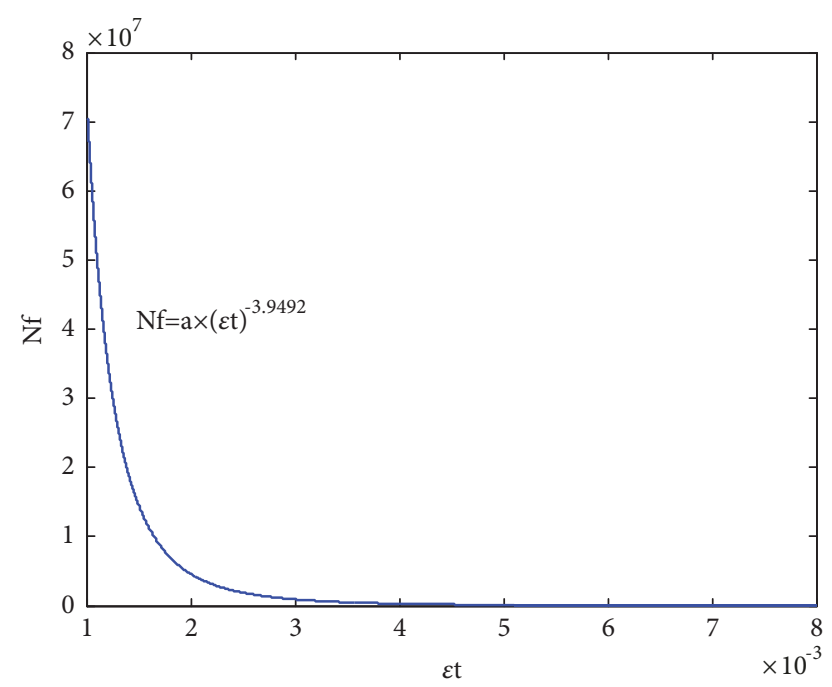

FIGURE 18: Relationship between the pavement fatigue life and the tensile strain at the layer bottom.

load), the rutting and fatigue life of asphalt pavement were calculated in terms of keeping load amplitude and load period unchanged, respectively. Through comparison analysis, some conclusions can be drawn as follows.

(1) Keeping the periods of the three load functions unchanged, their amplitudes are varied (increasing 1.06 times of half-sinusoidal load, 1.35 times of triangular load, and 1.31 times of vertical stepwise load functions, respectively) to reduce their simulation error against the moving traffic load. This allows a better simulation of the moving load condition.
(2) The amplitudes of the three load functions remain unchanged while their periods are varied (increasing 1.07 times of the half-sinusoidal load, increasing 2.23 times of the triangular load, and increasing 2.1times of the vertical stepwise load). This results in a better simulation of the moving load condition and reduced simulation errors.

(3) Regardless of whether the load amplitudes or the load periods are altered, the moving traffic load is well simulated. This excellently proves the "time-load equivalence" principle.

(4) Modifying the material parameters of the asphalt pavement has no effects on the multiple relationships of the periods and amplitudes between the three simulation load conditions and the calculated results of the moving traffic load.

(5) The fatigue life of the asphalt pavement is only related to peak load value, but not the loading patterns.

(6) In order to ensure the equivalent rutting and fatigue life under the four load conditions simultaneously, the relationship between the peak load values and the load periods was obtained through comparison during application.

Although the analysis in this paper is lack of the experimental result to conduct comparison to validate the analytical and numerical solution, it provides an insight into understanding the effect and equivalence of different loads applied on the asphalt pavement, which can be applied in the field of simulation and calculation related to the dynamical analysis, rutting, and fatigue life evaluation.

\section{Data Availability}

The data used to support the findings of this study are available from the corresponding author upon request.

\section{Conflicts of Interest}

We declare that there are no conflicts of interest regarding the publication of this paper.

\section{Acknowledgments}

This research has been supported by the National Natural Science Foundation (Grant No. 51308554) to the first author. The author also appreciates the Guizhou Transportation Science and Technology Foundation (Grant Nos. 2013-121-013 and 2019-122-006), the Hunan Transportation Science and Technology Foundation (Grant Nos. 201237 and 201622), and the Central South University Graduate Student Innovation Fund Project (2015zzts062).

\section{References}

[1] H. Dan, J. Tan, and J. Chen, "Temperature distribution of asphalt bridge deck pavement with groundwater circulation temperature control system under high- and low temperature conditions," Road Materials and Pavement Design, vol. 20, no. 3, pp. 509-527, 2018.

[2] H. Dan, L. He, and B. Xu, "Experimental investigation on nondarcian flow in unbound graded aggregate material of highway 
pavement," Transport in Porous Media, vol. 112, no. 1, pp. 189206, 2016.

[3] L. S. Gao, H. C. Dan, and J. Q. Chen, "Research on predicting the rutting of asphalt pavement based on a simplified burgers creep model," Mathematical Problems in Engineering, vol. 2017, Article ID 3459704, 14 pages, 2017.

[4] R. V. Siddharthan, J. Yao, and P. E. Sebaaly, "Pavement strain from moving dynamic 3D load distribution," Journal of Transportation Engineering, vol. 124, no. 6, pp. 557-566, 1998.

[5] R. V. Siddharthan, N. Krishnamenon, M. El-Mously, and P. E. Sebaaly, "Investigation of tire contact stress distributions on pavement response," Journal of Transportation Engineering, vol. 128, no. 2, pp. 136-144, 2002.

[6] R. V. Siddharthan, P. E. Sebaaly, M. El-Desouky, D. Strand, and D. Huft, "Heavy off-road vehicle tire-pavement interactions and response," Journal of Transportation Engineering, vol. 131, no. 3, pp. 239-247, 2005.

[7] H. Dan, Z. Zhang, J. Chen, and H. Wang, "Numerical simulation of an indirect tensile test for asphalt mixtures using discrete element method software," Journal of Materials in Civil Engineering, vol. 30, no. 5, pp. 1-11, 2018.

[8] Y. Yang, H. Hung, and D. Chang, "Train-induced wave propagation in layered soils using finite/infinite element simulation," Soil Dynamics and Earthquake Engineering, vol. 23, no. 4, pp. 263-278, 2003.

[9] P. Khavassefat, D. Jelagin, and B. Birgisson, "Dynamic response of flexible pavements at vehicle-road interaction," Road Materials and Pavement Design, vol. 16, no. 2, pp. 256-276, 2014.

[10] "American Association of State Highway and Transportation Officials," The AASHO road test, report7, summary report Report61G, Highway Research Board, 1962.

[11] N. Garg and M. R. Thompson, "Structural response of LVR flexible pavements at $\mathrm{mn} /$ road project," Journal of Transportation Engineering, vol. 125, no. 3, pp. 238-244, 1999.

[12] I. L. Al-Qadi, A. Loulizi, M. Elseifi, and S. Lahouar, "The Virginia smart road: the impact of pavement instrument on understanding pavement performanc," Journal of the Association of Asphalt Paving Technoligists, vol. 73, pp. 427-465, 2004.

[13] Z. Ge, H. Wang, Y. Wang, and X. Hu, "Evaluating fatigue behavior of asphalt mixtures under alternate tension-compression loading model using new alternate biaxial splitting method," Construction and Building Materials, vol. 54, pp. 106-112, 2014.

[14] Q. Ye, S. Wu, and N. Li, "Investigation of the dynamic and fatigue properties of fiber-modified asphalt mixtures," International Journal of Fatigue, vol. 31, no. 10, pp. 1598-1602, 2009.

[15] R. K. Abu Al-Rub, M. K. Darabi, C.-W. Huang, E. A. Masad, and D. N. Little, "Comparing finite element and constitutive modelling techniques for predicting rutting of asphalt pavements," International Journal of Pavement Engineering, vol. 13, no. 4, pp. 322-338, 2012.

[16] H. Dan, L. He, and B. Xu, "Experimental investigation on skid resistance of asphalt pavement under various slippery conditions," International Journal of Pavement Engineering, vol. 18, no. 6, pp. 485-499, 2015.

[17] American Association for State Highway and Transportation Officials, "Determining the resilient modulus of soils and aggregate materials," in Standard Specifications for Transportation Materials and Methods of Sampling and Testing, AASHTO, Wash, DC, USA, 20th edition, 2003.
[18] C. L. Monsmith, N. Ogawa, and R. Freeme, Permanent Deformation Characteristics of Subgrade Soils Due to Repeated Loading, Transportation Research Board, Washington, DC, USA, 1975.

[19] P. Kettil, B. Lenhof, K. Runesson, and N.-E. Wiberg, "Simulation of inelastic deformation in road structures due to cyclic mechanical and thermal loads," Computers \& Structures, vol. 85, no. 1-2, pp. 59-70, 2007.

[20] H. Dan, Z. Zhang, X. Liu, and J. Chen, “Transient unsaturated flow in the drainage layer of a highway: solution and drainage performance," Road Materials and Pavement Design, vol. 20, no. 3, pp. 528-553, 2018.

[21] J. M. Roesset, Stiffness and Damping Coefficients of Foundations. Dynamic Response of Structures: Experimentation, ASCE, New York, NY, USA, 1980.

[22] X. Z. Cui and Q. Jin, "The dynamic response of saturated asphalt pavement under wheel loads," Journal of Shandong University (Engineering Science), vol. 38, no. 5, pp. 19-24, 2008.

[23] Y. H. Huang, Pavement Analysis and Design, Prentice Hall, New Hersey, NJ, USA, 1993.

[24] D. D. Theodorakopoulos, "Dynamic analysis of a poroelastic half-plane soil medium under moving loads," Soil Dynamics and Earthquake Engineering, vol. 23, no. 7, pp. 521-533, 2003.

[25] R. Siddharthan, Z. Zafir, and G. M. Norris, "Moving load response of layered soil. I: Formulation," Journal of Engineering Mechanics, vol. 119, no. 10, pp. 2052-2071, 1993.

[26] R. Siddharthan, Z. Zafir, and G. M. Norris, "Moving load response of layered soil .II: formulation," Journal of Engineering Mechanics-ASCE, vol. 119, no. 10, pp. 2072-2089, 1993.

[27] G. Y. Liao, "The adhibition of ABAQUS in road engineering," 2008.

[28] H.-C. Dan, L.-H. He, J.-F. Zou, L.-H. Zhao, and S.-Y. Bai, "Laboratory study on the adhesive properties of ice to the asphalt pavement of highway," Cold Regions Science and Technology, vol. 104-105, pp. 7-13, 2014.

[29] H.-C. Dan, L.-H. He, and L.-H. Zhao, "Experimental investigation on the resilient response of unbound graded aggregate materials by using large-scale dynamic triaxial tests," Road Materials and Pavement Design, pp. 1-18, 2019. 


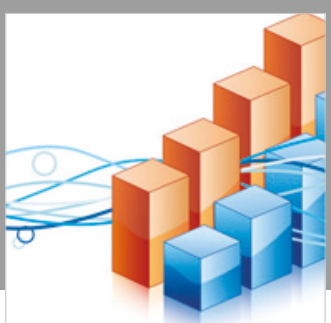

Advances in

Operations Research

\section{-n-m}
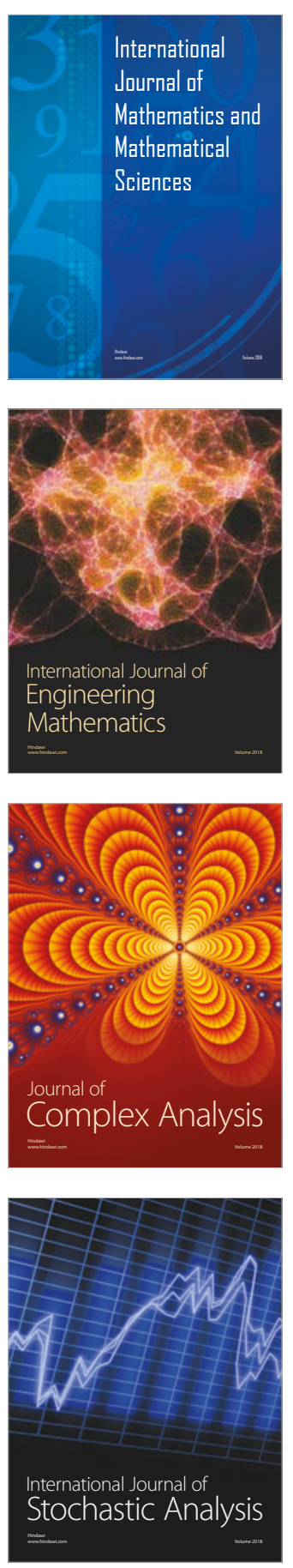
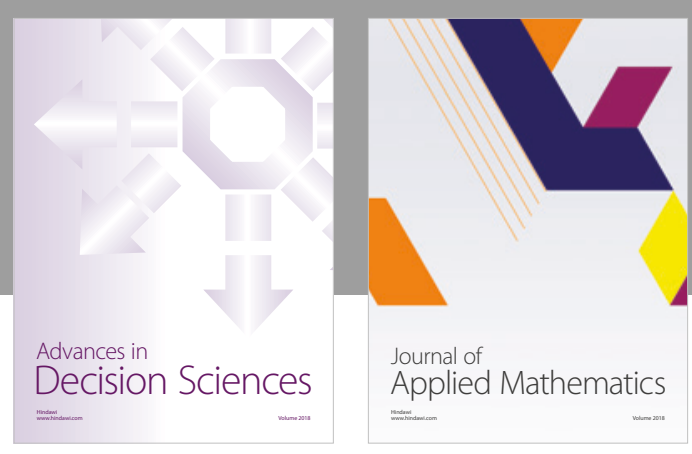

Journal of

Applied Mathematics
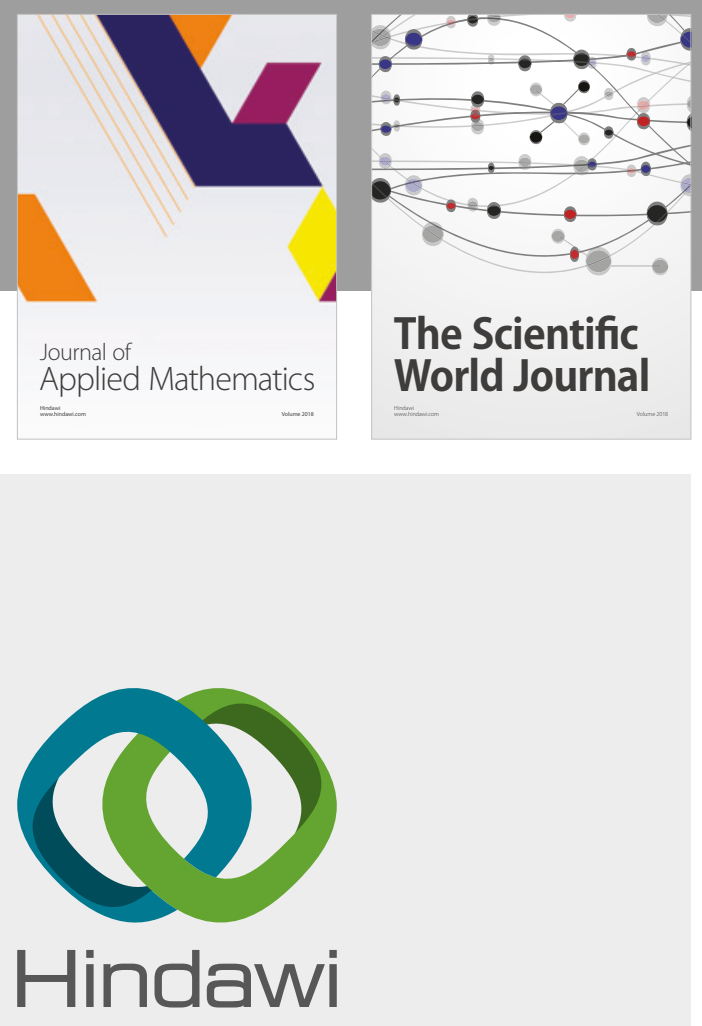

Submit your manuscripts at

www.hindawi.com

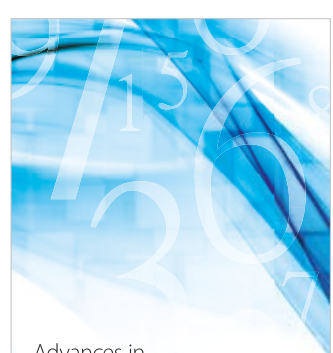

Advances in
Numerical Analysis
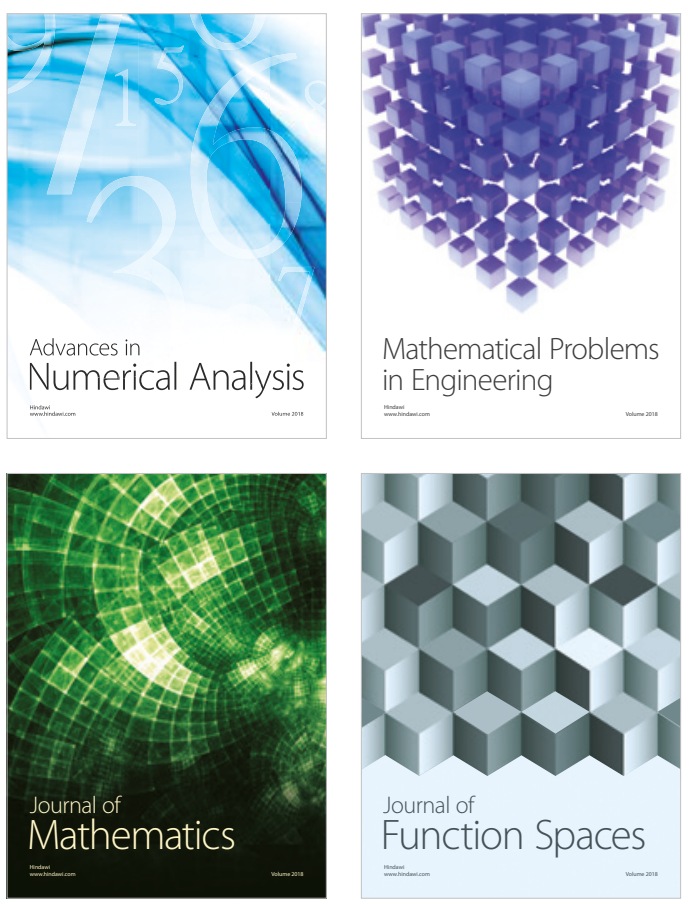

Mathematical Problems in Engineering

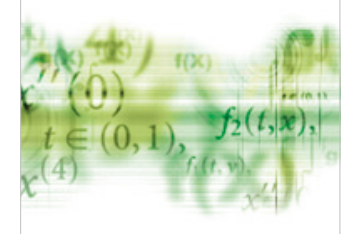

International Journal of

Differential Equations

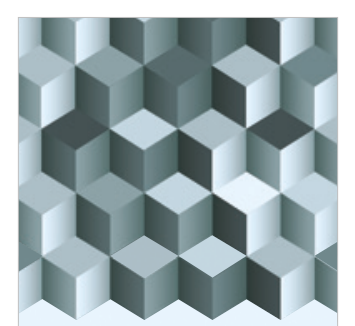

Journal of

Function Spaces

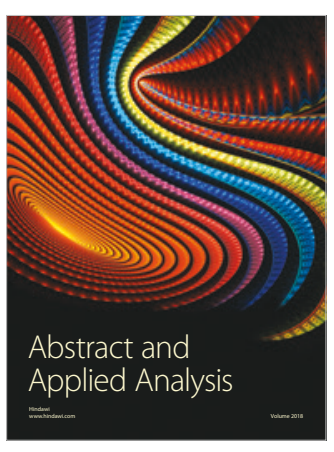

The Scientific

World Journal

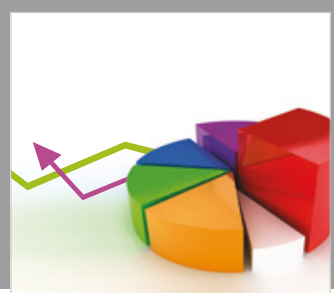

Journal of

Probability and Statistics
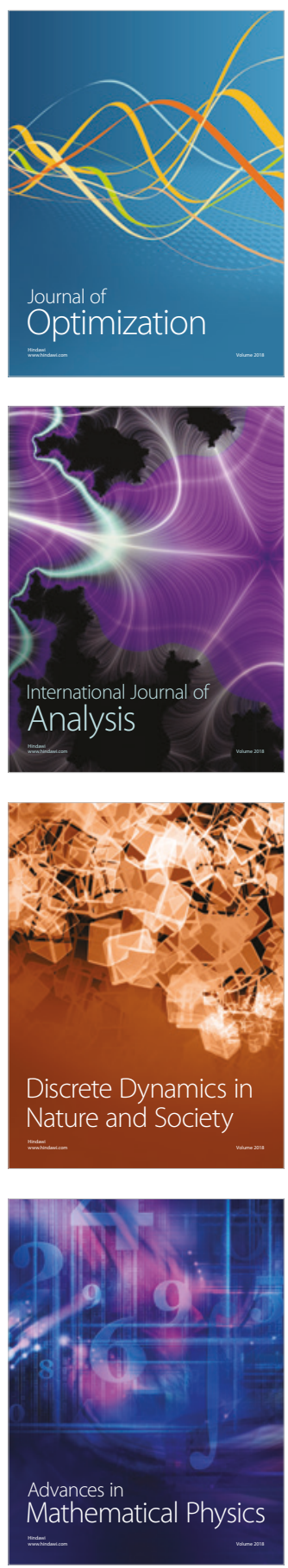